\title{
ARQUiTECTURA OFICIAL CONTEMPORÁNEA Y ESPACIO SOCIAL EN LAS ESCUELAS RURALES DE MONTAÑA EN EL CONTEXTO DE LAS COMUNIDADES INDÍGENAS TUCUMANAS (ARgENTINA)
}

\author{
Contemporary Official Architecture and Social Space \\ in Rural Mountain Schools in the Context of The \\ Indigenous Communities of Tucuman (Argentina)
}

\author{
Gabriela Soledad Varela Freire* \\ doi: https://doi.org/10.31644/ED.V9.N1.2022.A02
}

\begin{abstract}
Resumen: El edificio escolar constituye el espacio en donde el Estado concibe la educación formal. Su arquitectura es un instrumento activo en los procesos de aprendizaje y en la formación de ciudadanía. A partir del año 2006, con la Ley de Educación Nacional, el Estado argentino buscó adecuar mecanismos de enseńanza para escuelas rurales y en comunidades indígenas con el objetivo principal de respetar sus idiosincrasias. Este artículo busca claves para aproximarse a la problemática sobre cómo el Estado resuelve la contradicción que se plantea a sí mismo entre la formación ciudadana homogeneizadora-disciplinadora que pretende impartir y el respeto por las identidades culturales en los ámbitos rurales de las comunidades indígenas. Para ello, se consideraron la dinámica del espacio social generado por la arquitectura escolar y aspectos temporales, espaciales y roles sociales durante eventos festivos-culturales de las comunidades y las escuelas. Se tomaron como casos de estudio tres escuelas rurales de montaña de Tucumán en tres comunidades indígenas. De este estudio se puede concluir que aunque existen vínculos construidos entre las comunidades educativas y las comunidades indígenas de los casos analizados, estas relaciones muchas veces reproducen los mecanismos de subordinación que el Estado ha venido imponiendo material (en el edificio escolar) y simbólicamente (en la práctica social). Como consecuencia, la participación activa de las comunidades indígenas en la toma de decisiones más importantes generalmente se ve limitada.
\end{abstract}

Palabras clave: arquitectura escolar, festividades comunitarias, políticas públicas, territorio.

\footnotetext{
* Doctorante en Arquitectura, Facultad de Arquitectura y Urbanismo de la Universidad Nacional de Tucumán, Argentina. ORCiD: https://orcid.org/0000-0002-6635-3007 Correo-e: varelafreiregabriela@gmail.com.

Fecha de recepción: 02/05/2021. Fecha de aceptación: 08/01/2022. Fecha de publicación: 31/01/2022.

\section{(cc) BY-NC-ND}

EntreDiversidades. Revista de Ciencias Sociales y Humanidades, Vol. 9, Núm. 1 (18), enero-junio 2022. Páginas: 46-75 ISSN-e: 2007-7610. https://doi.org/10.31644/ED.V9.N1.2022.A02 
Abstract: The school building is the space where the State conceives formal education. Its architecture is an active instrument in the learning processes and in the formation of citizenship. Since 2006, with the National Education Law, the Argentine State has sought to adapt teaching mechanisms for rural schools and indigenous communities with the main objective of respecting their idiosyncrasies. This article looks for clues to approach the problem of how the State resolves the contradiction that it poses to itself between the homogenizing-disciplining civic formation that it intends to impart and the respect for the cultural identities in the rural areas of indigenous communities. The dynamics of the social space generated by the proposed school architecture and temporal, spatial and social roles during festive-cultural events of communities and schools were considered. Three rural mountains schools in Tucumán in three indigenous communities were taken as case studies. From this study it can be concluded that although there are built links between the educational communities and the indigenous communities of the cases analyzed, these relationships often reproduce the mechanisms of subordination that the State has been imposing materially (in the school building) and symbolically (in social practice). As a result, the active participation of indigenous communities in the most important decisions is often limited.

Keywords: school architecture, community festivities, public policies, territory.

\section{Introducción}

En el territorio argentino, la educación sistematizada y desde un marco occidental fue iniciada por la Compañía de Jesús en 1624, teniendo su primer desarrollo significativo durante el siglo XIX, cuando se la toma como una de las herramientas fundamentales para organizar y establecer las bases de la nueva nación (Guibert, 1988). Asimismo, a fines de ese siglo se sanciona la Ley de Educación Común No 1420 (1884), con la que se establece la educación como universal, gratuita, laica y obligatoria. En la misma, se indica que en las colonias o territorios existiría una escuela pública cada 300 o 500 habitantes y que en aquellas zonas de campańa con población dispersa se establecerían escuelas ambulantes (LEC, 1884). A su vez, en el año 1905 se promulga la Ley $\mathrm{N}^{\circ}$ 4874 o Ley Láinez, a partir de la cual se autoriza al Estado nacional a crear escuelas elementales, infantiles, mixtas y rurales en aquellas provincias que lo solicitaran a fin de reducir los niveles de analfabetismo detectados en la época (Pineau, et al., 2007). Como consecuencia de la aplicación de estas leyes, se da un incremento significativo de la cantidad de escuelas, alumnos y profesores; y la educación, aparte de resolver la situación de analfabetismo en los sectores más diversos de la sociedad, se instala como un mecanismo de control, normalización y disciplinamiento de la población (Tedesco, 2003; Pineau, et al., 2007; Sasiain, 2015).

Fue un momento histórico donde lo político se caracterizó por un gobierno nacional federal que sostenía el culto católico, y lo social por su gran heterogeneidad de culturas, ideologías y clases sociales. La mayor parte de la población, casi el 70 \%, habitaba zonas rurales (Lobato y Suriano, 2000), por lo que las escuelas rurales, de campańa y ambulantes fueron de tal importancia que hasta incluso constituyeron parte de los artefactos estatales y políticos que emplearon los unitarios

EntreDiversidades. Revista de Ciencias Sociales y Humanidades, Vol. 9, Núm. 1 (18), enero-junio 2022. Páginas: $46-75$ ISSN-e: 2007-7610. https://doi.org/10.31644/ED.V9.N1.2022.A02 
para civilizar a la "barbarie" federal. ${ }^{1}$ Sin embargo, fueron establecimientos en los que se impartió una educación del mínimum de instrucción obligatoria circunscripta a escritura, lectura, historia y geografía nacional, disciplinas que igualmente permitían conseguir la homogeneización de la sociedad y generar las bases para una cultura nacional argentina, tan buscada en ese momento (Pineau, et al., 2007).

Hoy en día, la escuela constituye el espacio por excelencia desde donde se continúa la búsqueda de integrar el ámbito rural a las esferas del Estado. A partir del año 2006, este interés iniciado desde fines del siglo XIX se incrementó con la creación de la modalidad de la educación rural $^{2}$ dentro de la estructura gubernamental, habilitándose la posibilidad de desarrollar políticas públicas dirigidas específicamente a este sector. Se buscó adecuar mecanismos de enseñanza a los contextos rurales intentando respetar sus idiosincrasias. Este principio define los objetivos ${ }^{3}$ de esta rama de la educación y determina qué se enseńa, cómo se hace y cómo se articula el sistema educativo con la comunidad y el territorio (LEN, 2006).

En este artículo se abordan tres aspectos que se interrelacionan entre sí y permiten contextualizar la situación de las escuelas que se buscan analizar: la educación rural, las comunidades indígenas rurales de la provincia de Tucumán y la arquitectura escolar como artefacto fundamental en los procesos de la educación formal y el desarrollo de los vínculos entre la comunidad educativa, el territorio y el Estado.

Para el Estado, la educación formal se concibe desarrollada solo en el espacio materializado que constituye el edificio escolar, la escuela; es el recurso físico básico con el que cuenta el sistema educativo para habilitar los procesos de enseñanza y aprendizaje (CyNBAE, 1998). Desde la Dirección de Infraestructura Escolar, se reconoce la importancia de considerar los requerimientos pedagógicos, las pautas de uso de las comunidades educativas y locales y los condicionantes territoriales y ambientales en la concepción global de la arquitectura escolar para así lograr una escuela que funcione como facilitadora de todas las actividades que se desarrollan (CyNBAE, 1998). A su vez, algunos autores señalan a la arquitectura escolar como el instrumento pedagógico por excelencia y como una variable activa en los procesos de aprendizaje; el edificio escolar no es neutral en tanto sus características ambientales, espaciales y materiales inciden en las dinámicas de aprendizaje, en los resultados obtenidos y en las pautas de uso de todos los miembros de la comunidad educativa (Viñao, 1993; Zarankin, 2001; Vital, 2014).

La escuela, aparte de ser una herramienta fundamental e imprescindible para la educación formal, también cumple un importante rol político, social y cultural dentro de la vida e historia de la comunidad. En zonas rurales aisladas, con población dispersa y de difícil accesibilidad como las zonas de alta montańa, la escuela suele ser el principal edificio estatal presente. Por lo

\footnotetext{
${ }^{1}$ Durante los ańos de organización nacional argentina se desarrollaron dos tendencias políticas, con propuestas opuestas de organización de las relaciones entre la distintas provincias que integraban el nuevo Estado, el federalismo (federales) y el centralismo (unitarios). En las primeras décadas del siglo XIX se enfrentaron en luchas y guerras civiles.

${ }^{2}$ Organización alternativa que procura garantizar la escolaridad obligatoria en territorios con menos de 2000 habitantes o población dispersa (LEN, 2006).

${ }^{3}$ Flexibilidad en propuestas pedagógicas, diseños institucionales y modelos de organización escolar a fin de fortalecer los vínculos con sus familias, medios de pertenencia, identidades culturales y actividades productivas (LEN, 2006).
}

EntreDiversidades. Revista de Ciencias Sociales y Humanidades, Vol. 9, Núm. 1 (18), enero-junio 2022. Páginas: 46-75 ISSN-e: 2007-7610. https://doi.org/10.31644/ED.V9.N1.2022.A02 
tanto, funciona como punto de encuentro entre el Estado y la comunidad y, a la vez, suele ser el espacio en donde se debaten temas de interés de la comunidad y se realizan diversidad de eventos culturales (Plencovich y Costantini (coords.), 2011; Racedo, et al., 2015).

En la Argentina, alrededor de 3600000 personas viven en zonas rurales y, más de 1600000 residen en la región del Norte Grande Argentino ${ }^{4}$ (NGA), coincidiendo con la zona del país en donde se encuentran una parte importante de las comunidades indígenas (INDEC, 2021). En la provincia de Tucumán más de 19000 personas se consideran descendientes de pueblos indígenas, y en los relevamientos ${ }^{5}$ realizados se constató la existencia de 16 comunidades integradas por más de 4160 familias que habitan alrededor de 456000 ha, mayormente zonas rurales montañosas (INDEC, 2021; Arenas, 2013; Arenas y Ataliva, 2017).

Las comunidades indígenas de la provincia de Tucumán, al igual que las del resto de la Argentina y de otros países de Latinoamérica, son consideradas grupos subalternos por parte de los Estados. Se distinguen del resto de la población rural especialmente por las movilizaciones y luchas que vienen realizando en relación al reconocimiento de sus derechos sobre los territorios que habitan y el respeto a sus culturas ancestrales (Trinchero, 2010). Sistemáticamente se criminalizaron y obstaculizaron sus reclamos, se invisibilizaron los conflictos a los que eran sometidas, se apropiaron de sus tierras y se las explotó como mano de obra (Garay, 2018; Arenas y Ataliva, 2017). A partir de 1990, ${ }^{6}$ con la promulgación del Convenio 169 de la Organización Internacional del Trabajo (OIT, 2014) y la inclusión de los artículos 75 inc. 17 en la Constitución Nacional (CNA, 1994) y 149 en la Constitución de la Provincia de Tucumán (CPT, 2006), se iniciaron procesos de reorganización y fortalecimiento de las comunidades indígenas. Aunque a partir de estos hechos las comunidades empezaron a tener un mayor respaldo legal para defender sus derechos, las desigualdades y desequilibrios territoriales aún persisten (Arenas y Ataliva, 2017). Actualmente, reclaman el reconocimiento de la propiedad comunitaria, una educación intercultural y una participación activa en la toma de decisiones sobre las políticas dirigidas a ellas (Arenas y Ataliva, 2017; Trinchero, 2010). Son un presente activo que viven procesos de reivindicación, recuperación, reconstrucción y reconfiguración de sus bienes patrimoniales, de sus memorias y saberes y de sus formas colectivas de organización socioeconómicas y políticas; derribando los conceptos de inferioridad que siempre les fueron atribuidos (Isla, 2002; Castellanos, et al., 2018).

El territorio es un componente importante de la identidad indígena y es la base de sus luchas y reivindicaciones. Justamente, es en el territorio donde se van a establecer y visibilizar las relaciones sociales que se dan entre la comunidad local y la institución educativa, por lo que resulta necesario señalar algunos conceptos que se consideran en este artículo sobre este término.

\footnotetext{
${ }^{4}$ Región comprendida por las provincias de Jujuy, Salta, Tucumán, Catamarca, Santiago del Estero, La Rioja, Formosa, Chaco, Misiones y Corrientes.

${ }^{5}$ A partir del ańo 2006 se promovió el Programa Nacional Relevamiento Territorial de Comunidades Indígenas, un relevamiento técnico jurídico y catastral de las tierras que ocupan (Arenas y Ataliva, 2017).

${ }^{6}$ Se reconoce su preexistencia étnico-cultural, el respeto a sus identidades, sus espiritualidades, sus instituciones y sus lenguas, la importancia de su relación con la Pachamama, el derecho de la posesión y propiedad comunitaria de sus tierras, a una educación bilingüe e intercultural y a su desarrollo político, social y cultural.
}

EntreDiversidades. Revista de Ciencias Sociales y Humanidades, Vol. 9, Núm. 1 (18), enero-junio 2022. Páginas: $46-75$ ISSN-e: 2007-7610. https://doi.org/10.31644/ED.V9.N1.2022.A02 
Algunos autores como Di Méo (1998) y Santos (1996, 2000) consideran al territorio como una construcción sociocultural que alude a lo local y a la cosmovisión de sus actores, definido por particularidades históricas, culturales, identitarias, ambientales e institucionales que se dan en un espacio y tiempo determinados. El territorio es dinámico y va modificándose en función de las actividades de las comunidades que lo habitan y las relaciones que se establecen y reformulan entre sus miembros. A su vez, el territorio está atravesado por relaciones de poder, el poder entendido como una relación de fuerzas físicas o simbólicas (Haesbaert, 2013). Es concebido como las relaciones de poder en y con el espacio donde están presentes las relaciones sociales. El espacio producido es el resultado de las prácticas del poder que se ejerce desde las resistencias o desde el Estado, por lo que es importante analizar estas prácticas. Es en el espacio en el que se dan las interrelaciones propias de todo proceso social en el que la identidad y la cultura estructuran una valorización territorial. Las relaciones espaciales son entendidas como enlaces afectivos, funcionales, económicos y políticos que los grupos crean con los espacios geográficos donde viven o atraviesan (Santos, 2000; Capel, 2016).

Disponer de un espacio físico para desarrollar la actividad educativa implica definir espacial, ambiental y materialmente ese artefacto que entendemos como escuela. Su materialidad, la relación entre los espacios y su organización, actúa sobre la percepción cotidiana e interpela la percepción espacial y funcional de las propias espacialidades construidas en las comunidades, en especial de las de las comunidades indígenas rurales que históricamente fueron estigmatizadas en sus modos de vida y saberes. El Estado, como actor hegemónico, tiene la capacidad de penetrar, cuestionar y modificar las pautas culturales de algunos sectores de la sociedad en su accionar civilizador y homogeneizador (Corrigan y Sayer, 2007).

Entendiendo la identidad como una construcción social y territorial de los seres humanos, sus sociedades y sus espacios, es el proceso de construcción de identidad el que transforma el espacio geográfico en espacio social (Alejandre, Ortiz e Izaguirre, 2018). Entonces, ¿qué carácter asume el espacio social del edificio escolar en el ámbito rural de las comunidades indígenas? El objetivo que se plantea aquí es esclarecer cómo resuelve el Estado la contradicción que se crea a sí mismo entre su formación ciudadana homogeneizadora-disciplinadora y el respeto por las identidades culturales en los ámbitos rurales. Para ello, se analizan las propuestas edilicias de tres escuelas rurales de montaña de Tucumán y la incidencia de la dinámica social de las comunidades indígenas involucradas. Para el análisis se consideraron los eventos festivos-culturales de las comunidades y las escuelas, teniendo en cuenta aspectos temporales, espaciales y roles sociales desempeñados.

A continuación, el trabajo se organiza con una sección en la que se indican los casos de estudio y la metodología llevada a cabo. Se avanza con otra en la que se hace mención a algunas características territoriales y culturales de las comunidades indígenas involucradas. En la siguiente sección, se analizan las estructuras arquitectónicas-espaciales de las escuelas en estudio. En otro apartado se describen las festividades que se practican en las comunidades indígenas y en las escuelas. A continuación, en tres secciones diferenciadas, se analizan las festividades identificadas considerando cómo se suceden en el tiempo, los actores involucrados, los roles que asumen y los usos de los espacios de las escuelas. Para finalizar, se presenta un apartado con las discusiones y otro con las conclusiones.

EntreDiversidades. Revista de Ciencias Sociales y Humanidades, Vol. 9, Núm. 1 (18), enero-junio 2022. Páginas: $46-75$ ISSN-e: 2007-7610. https://doi.org/10.31644/ED.V9.N1.2022.A02 


\section{Presentación de casos de estudio y trabajo de campo}

Los casos de estudio corresponden a tres escuelas rurales de alta montaña de Tucumán emplazadas en zonas habitadas por comunidades indígenas organizadas. Escuela $\mathrm{N}^{\circ} 379$ de Lara, Dpto. Tafí del Valle, a 3300 msnm; Escuela Nº 349 de Norco, Dpto. Trancas, a 1300 msnm; y Escuela No 214 Ramón Julián Valverdi de Gonzalo, Dpto. Trancas, a 1350 msnm. Todas están vinculadas con las comunidades indígenas Diaguita Calchaquí Potrero Rodeo Grande, Los Chuschagasta y Pueblo de Tolombón, respectivamente. ${ }^{7}$

Para la selección de las escuelas se partió de la categorización de escuelas rurales que el Ministerio de Educación realizó en el marco del Programa Nacional Mapa Educativo durante los años 2010-2016. Distinguieron 4 grupos de escuelas en función del grado de comunicación que presentaban con el sistema educativo (SE), en términos territoriales. Aquellas escuelas que presentaban mayor complejidad y dificultad para relacionarse con el resto del SE se denominaron "escuelas rurales de muy difícil acceso" (ERMDA); en la provincia de Tucumán 23 escuelas cumplían con esas características. Se hizo una selección de aquellas ERMDA en zonas habitadas por comunidades indígenas a una altitud mayor a los $1300 \mathrm{msnm}$, obteniendo una muestra de 14 establecimientos. Se escogieron aquellos que presentaban la mayor y menor altitud, compartían el nivel secundario itinerante, desarrollaban actividades en conjunto y en los que las comunidades indígenas involucradas mantenían lazos familiares y territoriales históricos; a la vez, son las escuelas a las que se pudo acceder.

Las tres escuelas elegidas son representativas de la dinámica social que se desarrolla en este tipo de establecimiento en estas áreas y comparten algunos aspectos en común. Tienen los niveles inicial y primario independientes, y a la vez comparten director y docentes del nivel secundario, quienes rotan entre las tres escuelas durante todo el año. Desde distintos sectores de la administración pública se realizan proyectos y actividades en conjunto entre las tres instituciones y las comunidades. Estas escuelas también comparten otros aspectos, como la baja matrícula general y la consecuente formación de aulas plurigrado, así como las largas distancias a recorrer de alumnos y docentes, por lo que pasan una gran parte del año en la institución. En este contexto se favorece el desarrollo de actividades culturales en las escuelas y la interacción social entre comunidad educativa e indígena en el espacio de la escuela.

${ }^{7}$ Están inscriptas en el Registro Nacional de Comunidades Indígenas (ReNaCI): Potrero Rodeo Grande desde 2003, Los Chuschagasta desde 2002 y Pueblo de Tolombón desde 2001. Este hecho les permitió constituirse como Comunidad Indígena desde el marco legal ante el Estado y la sociedad en general (Arenas y Ataliva, 2017).

EntreDiversidades. Revista de Ciencias Sociales y Humanidades, Vol. 9, Núm. 1 (18), enero-junio 2022. Páginas: $46-75$ ISSN-e: 2007-7610. https://doi.org/10.31644/ED.V9.N1.2022.A02 
Figura 1. Comunidades indígenas y escuelas a analizar Tucumán-Argentina
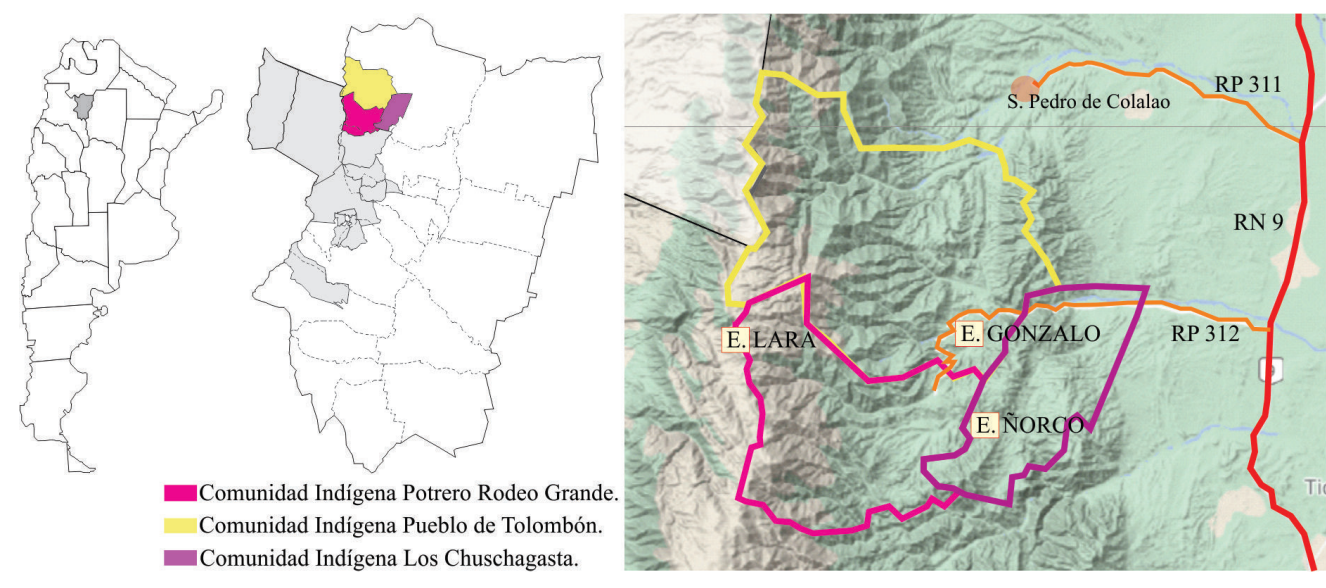

Fuente: Elaboración propia con base en mapa de Google Maps y de MDPT (2020).

Para el desarrollo del trabajo se realizaron viajes de campo a las escuelas y comunidades durante los años 2017, 2018 y 2019. En esas instancias se efectuaron entrevistas, observación no participante y se compartieron actividades comunitarias, como esquila de ovejas y talleres en las escuelas. A su vez, se realizaron entrevistas a funcionarios estatales encargados de la construcción de estos establecimientos. Durante el año 2020, por el contexto de pandemia y la consecuente inaccesibilidad al sitio, se mantuvieron entrevistas telefónicas con directores de las escuelas, funcionarios estatales que desarrollan actividades en el territorio, miembros de las comunidades indígenas y caciques.

\section{El espacio de las comunidades indígenas de alta montaña}

Las comunidades involucradas se encuentran emplazadas en las Cumbres Calchaquíes y Cuenca de Tapia-Trancas, limitan entre sí a la vez que comparten espacios de pastoreo y recolección. La comunidad Potrero Rodeo Grande está integrada por 103 familias dispersas en un territorio de 23000 ha en distintos pisos ecológicos, algunas familias son trashumantes durante el ańo, tienen uno o más puestos y comparten territorio de pastoreo y recolección con la comunidad indígena Amaicha del Valle. La comunidad Los Chuschagasta está integrada por 100 familias y cubren 15500 ha de los parajes de El Chorro, El Norco, La Higuera y Chuscha. La comunidad Pueblo de Tolombón se encuentra organizada en Comunidades de Base - Potrero, Gonzalo, Rearte, Tacanas Chica, Tacanas Grande y Hualinchay_-, suman un total de 311 familias y ocupan 41600 ha distribuidas en distintos pisos ecológicos (Arenas y Ataliva, 2017; Racedo, et al., 2015; Varela, 2019).

Algunos de los aspectos que comparten están relacionados con sus espiritualidades, organización socio-política, toma de decisiones mediante asambleas y realización de actividades de forma comunitaria. La vida comunitaria es el eje central de su identidad y su organización

EntreDiversidades. Revista de Ciencias Sociales y Humanidades, Vol. 9, Núm. 1 (18), enero-junio 2022. Páginas: $46-75$ ISSN-e: 2007-7610. https://doi.org/10.31644/ED.V9.N1.2022.A02 
repercute en las características de los espacios donde la desarrollan, muchas de ellas asociadas a actividades festivas y productivas. En tal sentido, las festividades más importantes corresponden a la veneración de la madre tierra y a los ciclos de las actividades productivas (Racedo, et al., 2015). Los principales organizadores de su vida cotidiana son el trabajo y la familia, dos aspectos que están en constante relación con el hábitat y el territorio. Las actividades cotidianas están a cargo del grupo familiar, cada miembro cumple con funciones complementarias e interdependientes entre sí. Se dedican principalmente al cultivo de la tierra y a la cría de ganado caprino y ovino; algunos miembros o familias enteras se desplazan por el territorio en distintas épocas del año en busca de comida y agua para los animales. En los últimos años, el área de estas comunidades está siendo explotada turística y deportivamente.

\section{La vivienda y sus usos}

En la mayoría de los poblados, las viviendas se encuentran dispersas. Se localizan sobre los terrenos de menor pendiente, próximos a puntos de agua — ríos, arroyos, ojos de agua — y resguardadas de los fuertes vientos. Están conformadas por conjuntos de tres o más construcciones separadas entre sí y ubicadas de manera tal que conforman un patio, un espacio común generalmente descubierto. Algunos pocos ejemplos cuentan con galerías entre las construcciones y los patios. Son viviendas que fueron construyéndose a lo largo del tiempo de forma agregativa. Por lo general, la agregación de nuevas construcciones corresponde a una nueva incorporación dentro de la familia ampliada. El conjunto se completa con huertas y corrales, ubicados en las inmediaciones. Un aspecto importante es la fluidez espacial y visual entre cocina-fogón, comedor, patio, huerta, corrales y espacio circundante.

Por lo habitual, la materialización de estas viviendas está resuelta con materiales y mano de obra del lugar, uso de adobe en la mayoría de las habitaciones, quincha ${ }^{8}$ en los espacios de fogón y depósito, madera para vigas de techos, entramado de cañas para cielorrasos, torta de barro o paja para cubiertas y pircas de piedra para la resolución de los corrales. A su vez, en las construcciones nuevas se observa la incorporación de materiales industrializados, como ladrillos cerámicos macizos, bloques de hormigón, cemento, cal, perfiles metálicos y chapas.

En cuanto a las actividades y usos en las viviendas, las mujeres tienden a ocupar los espacios de la cocina y el fogón, el patio — donde se hacen actividades manuales - y la huerta familiar; mientras que los hombres se encargan principalmente del manejo y cuidado del ganado en el espacio exterior y los corrales. El patio - y el comedor cuando existe individualizado- son los espacios que comparten todos los miembros de la familia en distintos momentos del día. Los dormitorios solo son usados para dormir y guardar cosas. El patio es el organizador funcional de la vivienda en la medida que vincula todos los espacios, a través de él se ingresa a los otros recintos, a la vez que se constituye como el eje principal de la vida cotidiana. Durante los eventos festivos y reuniones de la comunidad, son las mujeres las que se encargan de la comida y permanecen un mayor tiempo en la cocina-fogón; y es el patio el que también toma un rol protagónico, dado que

\footnotetext{
${ }^{8}$ Sistema constructivo constituido por un entramado de madera — generalmente cańas de la zona- y en el que se cubren las paredes exteriores e interiores con una mezcla de barro y paja.
}

EntreDiversidades. Revista de Ciencias Sociales y Humanidades, Vol. 9, Núm. 1 (18), enero-junio 2022. Páginas: $46-75$ ISSN-e: 2007-7610. https://doi.org/10.31644/ED.V9.N1.2022.A02 
allí se suele encontrar la boca de la Pachamama9 y es donde se suele hacer el almuerzo y las otras actividades, como debates, juegos o bailes. Las actividades relacionadas al ganado se practican en los corrales y en sus inmediaciones.

Figura 2. Viviendas de las zonas de estudio

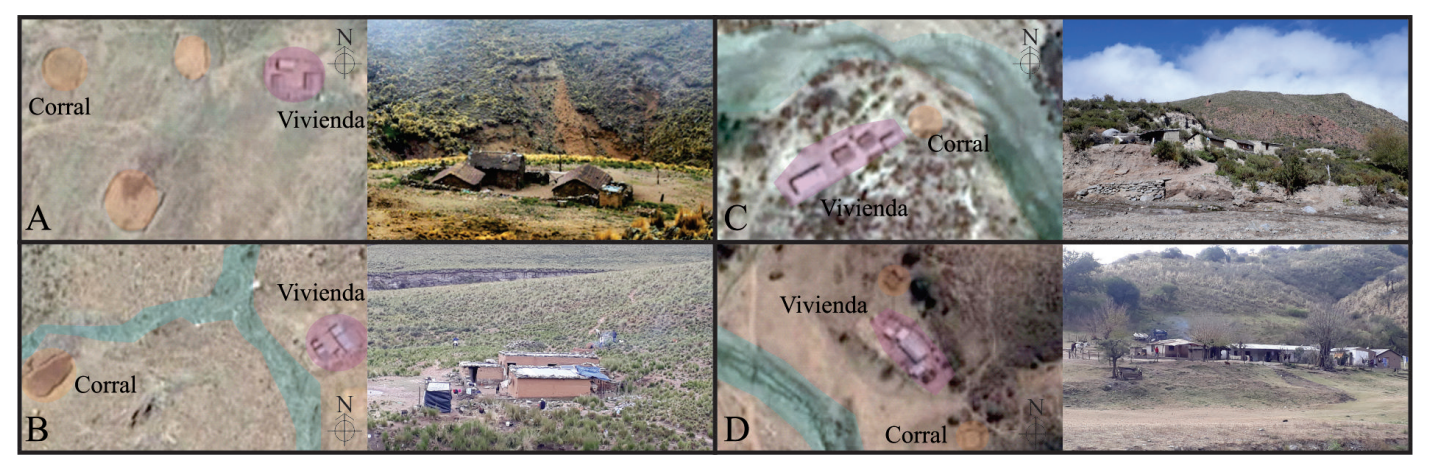

Fuente: Elaboración propia con base en mapa georreferenciado de Google Maps. Autora: Gabriela S. Varela Freire. Fecha: 2018. Lugar: Lara y Ñorco, Tucumán, Argentina.

Figura 3. Vivienda B. Espacios, zonificación funcional y modelo Gamma
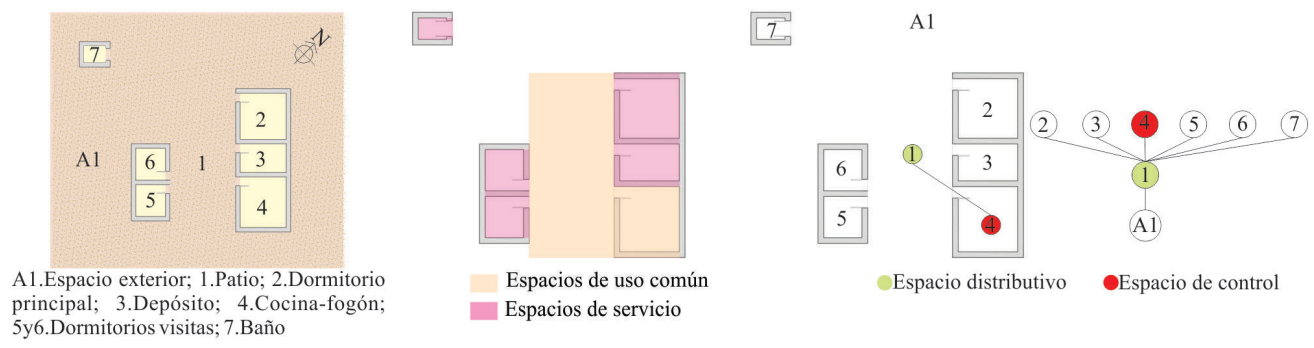

Fuente: Elaboración propia con base en la vivienda B de la Figura 2.

\section{Estructura espacial de las escuelas}

La estructura arquitectónica de las escuelas se analizó haciendo hincapié en aspectos funcionales y espaciales. Se analizaron las plantas, identificando los distintos espacios y estableciendo zonificaciones de uso diferenciando actividades educativas, albergue, uso común, servicios, circulaciones y dirección. Para profundizar el análisis se tomó como referencia la metodología aplicada por Zarankin (2001), quien analiza la distribución espacial en las escuelas a través del "Modelo Gamma". Este diagrama permite entender la estructura del edificio, circulaciones,

${ }^{9}$ Pozo que se hace en la tierra para depositar las ofrendas durante la celebración de la Pachamama. Permanece tapado con alguna piedra durante todo el año.

EntreDiversidades. Revista de Ciencias Sociales y Humanidades, Vol. 9, Núm. 1 (18), enero-junio 2022. Páginas: 46-75 ISSN-e: 2007-7610. https://doi.org/10.31644/ED.V9.N1.2022.A02 
organización espacial y obtener un panorama básico sobre cómo los mecanismos de control y poder se encuentran presentes en una determinada estructura (Zarankin, 2001). Se pueden distinguir espacios y estructuras distributivos (presentan 3 o más conexiones por nodo) o no distributivos (presentan 1 o 2 conexiones). Se considera que en las estructuras distributivas el poder y control están distribuidos de manera homogénea y tienen un carácter más democrático, mientras que en las estructuras no distributivas pasa todo lo contrario, priorizando algunos espacios en relación a otros que se jerarquizan notablemente (Zarankin, 2001).

\section{Escuela de Lara}

Esta escuela se fundó entre los años 1953 y 1954 . En sus inicios, la escuela funcionó en la casa de uno de los vecinos, años más tarde se construyó la parte original a partir de la gestión de la comunidad; en el año 2010 se realizó una ampliación en el marco del Programa Mejoramiento del Sistema Educativo, ${ }^{10}$ única modificación registrada. En ambas construcciones se usaron adobes fabricados en el lugar, aunque la ampliación fue proyectada y licitada con materiales industrializados, pero por las dificultades en el acceso se recurrió al uso de materiales del lugar. La construcción original contaba con cubierta de paja y vigas de madera que fueron cambiadas por chapas y perfiles metálicos en el momento de la ampliación. Las paredes están revocadas y pintadas con materiales industrializados.

Figura 4. Escuela No 379 (E), Centro de Atención Primaria de la Salud (CAPS) (C) y capilla $(\mathbf{C a})$

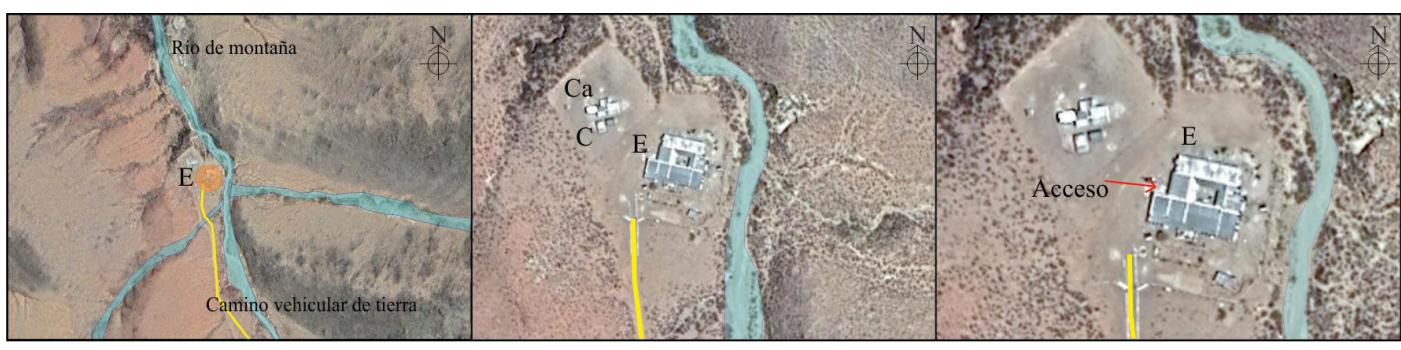

Fuente: Elaboración propia con base en mapa georreferenciado de Google Maps.

Es la única escuela de la provincia que actualmente mantiene un ciclo lectivo de montaña, empiezan las clases en septiembre y finalizan en mayo, fechas que se modificaron en los últimos años (comenzando las clases en octubre y finalizando en junio), adecuándose a las dinámicas trashumantes de la comunidad. Para el año 2019 contaban con una matrícula de 16 alumnos y tanto los alumnos como preceptores y docentes permanecen albergados en la escuela durante los cinco días de la semana.

\footnotetext{
${ }^{10}$ Este Programa Nacional se desarrolla a partir del año 2004 con los objetivos de mejorar la oferta y calidad educativa y optimizar las instalaciones edilicias de los establecimientos educativos a partir del subprograma "expansión de infraestructura escolar”, mediante el cual se plantea la construcción de más de 700 establecimientos (MPFIPyS, 2016).
}

EntreDiversidades. Revista de Ciencias Sociales y Humanidades, Vol. 9, Núm. 1 (18), enero-junio 2022. Páginas: $46-75$ ISSN-e: 2007-7610. https://doi.org/10.31644/ED.V9.N1.2022.A02 
Figura 5. Planta actual Escuela $N^{\circ} 379$. Espacios, zonificación funcional y modelo Gamma

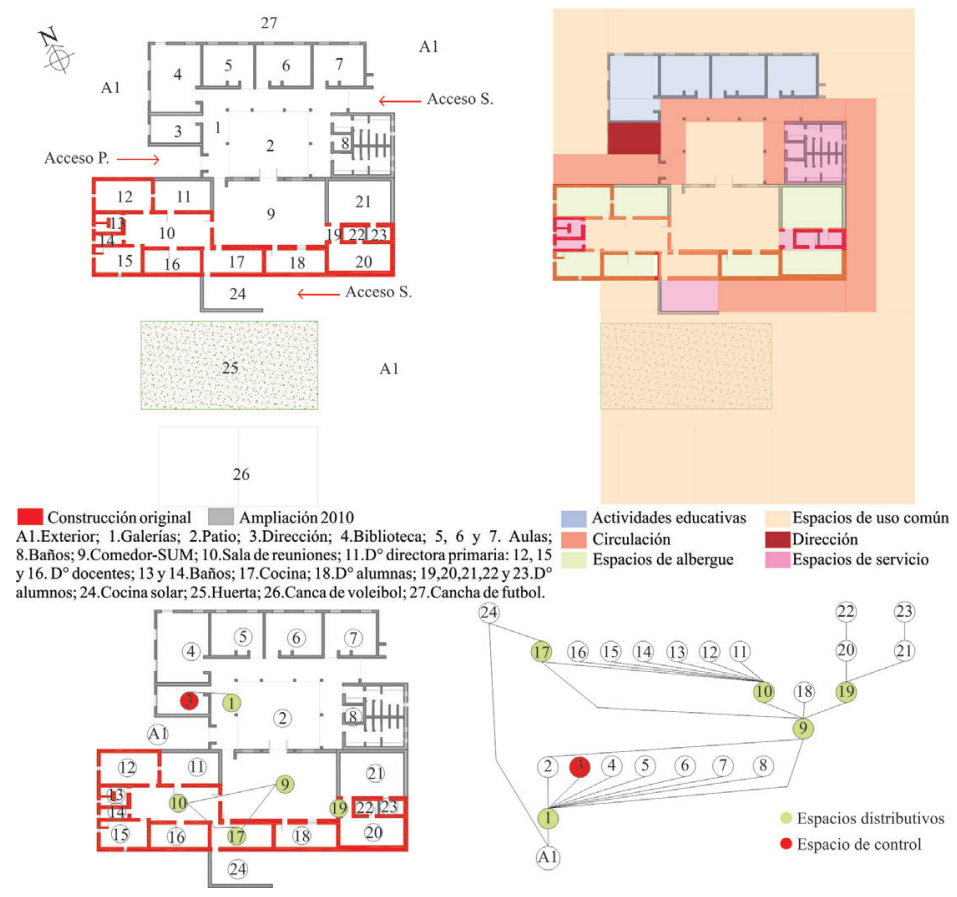

Fuente: Elaboración propia con base en planos facilitados por la Dirección de Materiales y Construcciones Escolares, Ministerio de Educación de Tucumán.

Como se observa, la estructura original presentaba una organización de los espacios en forma lineal y la mayoría abría hacia un espacio exterior que funcionaba como patio de perímetro libre, permitiendo una relación visual y espacial directa con el entorno inmediato. A partir de la ampliación, en donde se optó por una estructura arquitectónica compacta y cerrada, este patio se cubre y se crea un patio rodeado en todo su perímetro por distintas dependencias que abren hacia él y se niegan funcional y espacialmente al exterior. La arquitectura actual de esta escuela, aunque mantiene el uso de materiales del lugar en muros, está en disonancia con los patrones arquitectónicos de las viviendas del sitio y la forma en que estas fueron evolucionando en el tiempo. La resultante formal de esta escuela, de volumen puro y color blanco, también rompe con las morfologías de las viviendas que mantienen a la vista los colores de los materiales locales.

En las dos estructuras se pueden diferenciar varias áreas de uso, sector de actividades educativas, zonas de albergue de alumnos y docentes, áreas de uso común, zonas de servicio; asimismo, en la estructura actual se incorporan espacios de circulación y la dirección. En la construcción original algunos espacios compartían varias funciones, como el espacio del comedor o de la radio; a partir de la ampliación se destinaron espacios a las diferentes funciones, como la dirección. En lo cotidiano esta no es tan usada y permanece cerrada, dado que los directores

EntreDiversidades. Revista de Ciencias Sociales y Humanidades, Vol. 9, Núm. 1 (18), enero-junio 2022. Páginas: $46-75$ ISSN-e: 2007-7610. https://doi.org/10.31644/ED.V9.N1.2022.A02 
de primaria y secundaria no están todos los días en el establecimiento. Por el contrario, son los espacios de sala de reunión y cocina donde los adultos están la mayor parte del tiempo y desde donde pueden controlar lo que hacen los alumnos y otros miembros de la escuela.

Al analizar el modelo Gamma se observa que la estructura arquitectónica actual es de tipo panóptico, y se jerarquizan los espacios de galería, comedor, sala de reuniones y cocina. Los espacios jerarquizados coinciden con la mayoría de los espacios distributivos. La dirección está en relación directa con el primer espacio distributivo, la galería. La disposición adyacente de ambos espacios se puede decir que no es casual, ya que en el diseño arquitectónico constituyen los espacios de control y vigilancia de quien ingresa a la institución y de todo lo que sucede en el sector educativo. En la estructura se evidencian otros espacios de control, la sala de reuniones y la cocina; se encuentran en relación directa entre ellos y con el comedor, donde los alumnos permanecen una gran parte del día. Así, en su conjunto la estructura arquitectónica de esta escuela es no democrática, de acuerdo a lo señalado por Zarankin (2001), por tanto, la existencia de varios espacios de control dan cuenta de una distribución de poder en el espacio y en el tiempo.

\section{Escuela de Norco}

Esta escuela se fundó en el año 1943 y desde sus inicios funcionó en este terreno. A lo largo del tiempo se efectuaron varias modificaciones, una antes de la década de 1990, otra entre los años 1994-1995, en el marco del Programa Plan Social Educativo, ${ }^{11}$ y otra en el año 2010, en el marco del Programa de Mejoramiento del Sistema Educativo. La construcción en la que hoy funciona el nivel secundario, originalmente fue pensada como sede del Centro de Atención Primara de la Salud (CAPS) de Norco. Este edificio nunca fue usado y en el año 2016 el Sistema Provincial de Salud (SIPROSA) lo cedió al nivel secundario, quien hasta el momento compartía espacio con el nivel primario.

Figura 6. Escuela N$^{\circ} 349$ (E), CAPS (C), capilla (Ca) y vivienda (V)

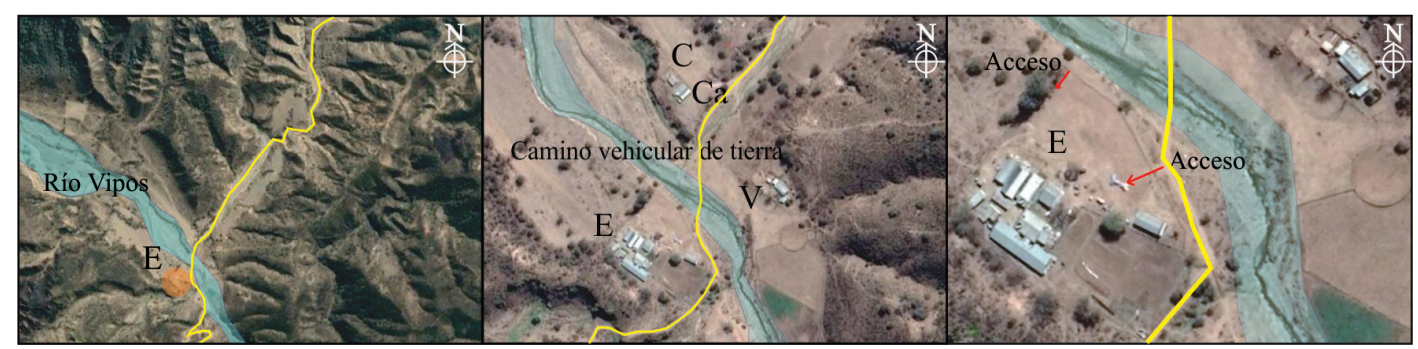

Fuente: Elaboración propia con base en mapa georreferenciado de Google Maps.

En las primeras construcciones se usaron materiales del lugar, como adobes y piedras para las paredes y paja para las cubiertas. Sin embargo, a partir de las intervenciones de la década de 1990, se recurrió al uso de materiales industrializados, como bloques de hormigón, se revocaron todas

\footnotetext{
${ }^{11}$ Este Programa Nacional se desarrolla a partir del año 1993 con el propósito de compensar las condiciones desiguales para el aprendizaje y se propone mejorar, reemplazar o ampliar la infraestructura escolar existente (MCyE, 1996).
}

EntreDiversidades. Revista de Ciencias Sociales y Humanidades, Vol. 9, Núm. 1 (18), enero-junio 2022. Páginas: 46-75 ISSN-e: 2007-7610. https://doi.org/10.31644/ED.V9.N1.2022.A02 
las paredes y las cubiertas de paja fueron reemplazadas por chapa. En un primer momento, se contó con personas del lugar y luego fueron las empresas que licitaron las obras y la Dirección de Materiales y Construcciones Escolares quienes proporcionaron la mano de obra necesaria y se encargaron de las construcciones y gestión de materiales.

Esta escuela históricamente mantuvo un ciclo lectivo de montaña, con clases de septiembre a mayo. Desde el año 2015, por disposiciones del Ministerio de Educación de Tucumán, se modificó el ciclo lectivo de marzo a diciembre. Para el año 2019 contaba con una matrícula de 46 alumnos. Al igual que en la escuela de Lara, los alumnos, preceptores y docentes permanecen albergados en la escuela durante los 5 días de la semana.

\section{Figura 7. Planta actual Escuela $N^{\circ} 349$. Espacios, zonificación funcional} y modelo Gamma

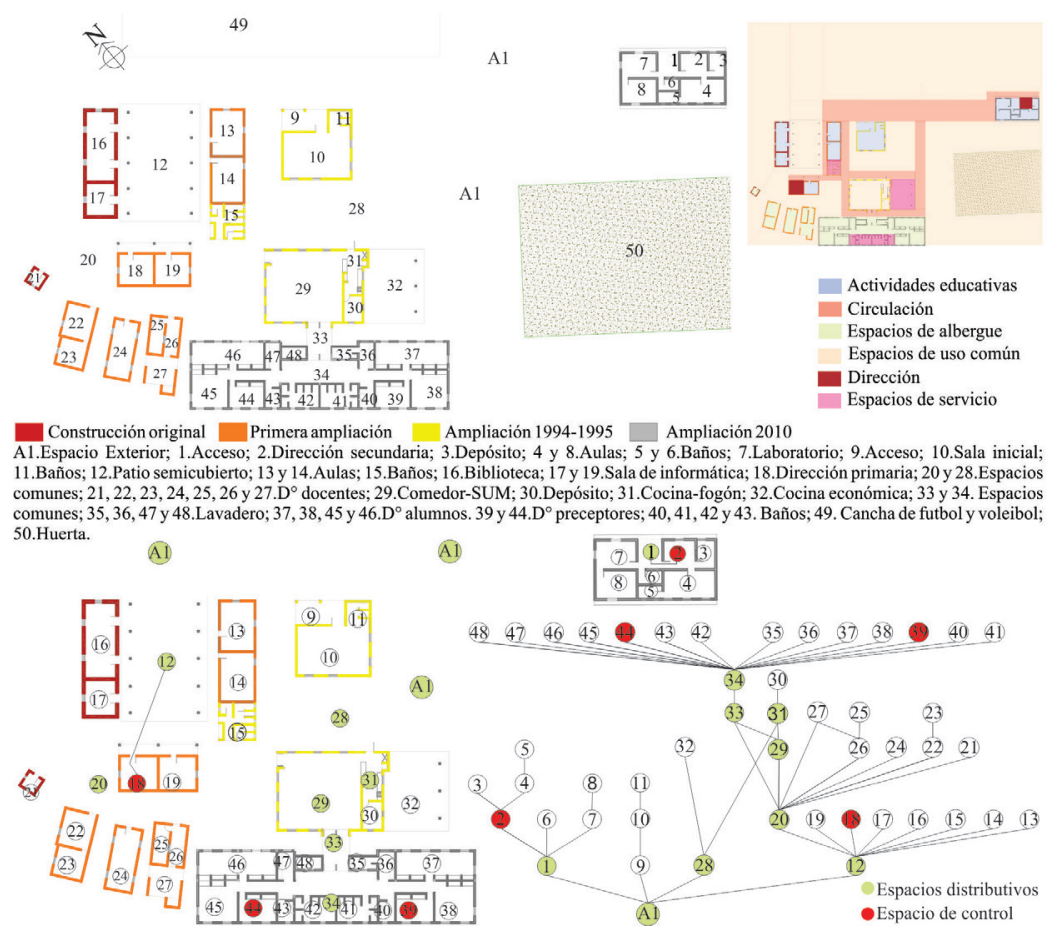

Fuente: Elaboración propia con base en planos facilitados por la Dirección de Materiales y Construcciones Escolares, Ministerio de Educación de Tucumán.

$\mathrm{Al}$ analizar esta escuela se observa que comparte algunas características con las viviendas del lugar, principalmente las construcciones hasta antes de la década del 90 que mantenían la materialidad y las formas de las mismas. Y aunque las nuevas construcciones hayan cambiado la materialidad tradicional del lugar por el uso de materiales industrializados, el conjunto en general mantiene un patrón de asentamiento similar al de las comunidades, dado que está compuesto por varios edificios separados entre sí y vinculados por el espacio exterior y caminerías. Se puede decir

EntreDiversidades. Revista de Ciencias Sociales y Humanidades, Vol. 9, Núm. 1 (18), enero-junio 2022. Páginas: $46-75$ ISSN-e: 2007-7610. https://doi.org/10.31644/ED.V9.N1.2022.A02 
que esta configuración espacial se debe principalmente a que se fue conformando a partir de la sumatoria de edificios a lo largo del tiempo sin una planificación integral. Cada uno de los edificios resuelve funciones específicas y fueron construidos por separado en distintos momentos.

La construcción más antigua corresponde al sector del nivel primario, constituido por tres edificios separados ubicados de tal forma que conforman un patio común (recientemente techado). Tanto el nivel inicial como nivel secundario, cocina-comedor y albergue de alumnos funcionan en distintos edificios independientes. El albergue de docentes y directores está configurado por construcciones separadas entre sí. Las aberturas principales de cada una de las construcciones están orientadas en dirección al río.

$\mathrm{Al}$ analizar el modelo Gamma se observan varios edificios con estructuras arquitectónicas no distributivas, en correspondencia a los sectores de nivel primario, nivel secundario y albergue de alumnos. Los espacios que se jerarquizan en el conjunto coinciden con los espacios distributivos — remarcados en verde- Con respecto a los espacios de control, las direcciones de los niveles primario y secundario se encuentran en relación directa a dos de los principales espacios distributivos, patio y hall de ingreso. En la práctica sucede lo mismo que en la escuela de Lara, por lo que estos espacios físicos casi no se usan y aparecen otros espacios desde donde se ejerce el control, la cocina y el comedor, durante el día, y los dormitorios de los preceptores, durante la noche. Esta distribución de poder también se ve favorecida por la diversidad de funciones que se dan en la vida cotidiana de la escuela y por la existencia de espacios que lo permiten.

\section{Escuela de Gonzalo}

Se fundó en el año 1919, y desde ese momento se realizaron alrededor de 6 ampliaciones, la última que se registra fue en el año 2008. Las primeras construcciones se hicieron con mano de obra y tecnologías constructivas locales, como el uso de adobe y piedras en las paredes y paja en cubiertas, y al igual que en los casos anteriores, en las últimas intervenciones realizadas en el marco de los Programas del Plan Social Educativo y Mejoramiento del Sistema Educativo se usaron materiales industrializados y se cambiaron las cubiertas de paja por chapa. También se observa que aunque la resultante arquitectónica actual es consecuencia de la sumatoria de construcciones realizadas a lo largo del tiempo como las viviendas del lugar, los aspectos morfológicos y espaciales difieren de las mismas.

Figura 8. Escuela $\mathrm{N}^{\circ} 214$ y secundaria (E)

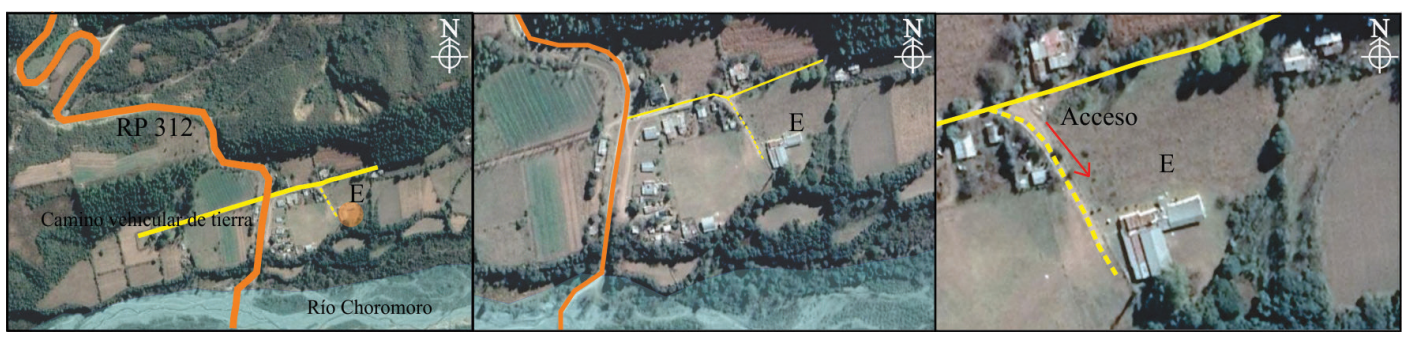

Fuente: Elaboración propia con base en mapa georreferenciado de Google Maps.

EntreDiversidades. Revista de Ciencias Sociales y Humanidades, Vol. 9, Núm. 1 (18), enero-junio 2022. Páginas: $46-75$ ISSN-e: 2007-7610. https://doi.org/10.31644/ED.V9.N1.2022.A02 
Con respecto al ciclo lectivo, este pasó por el mismo proceso que la escuela de Ñorco. Para el año 2019 contaba con una matrícula de 48 alumnos. En comparación con las otras dos escuelas, la distancia a recorrer por los alumnos es más reducida y presenta una mayor accesibilidad para los docentes, por lo que se optó por una modalidad de jornada completa de 8 horas diarias.

\section{Figura 9. Planta actual Escuela $\mathrm{N}^{\circ} 214$. Espacios, zonificación funcional y modelo Gamma}

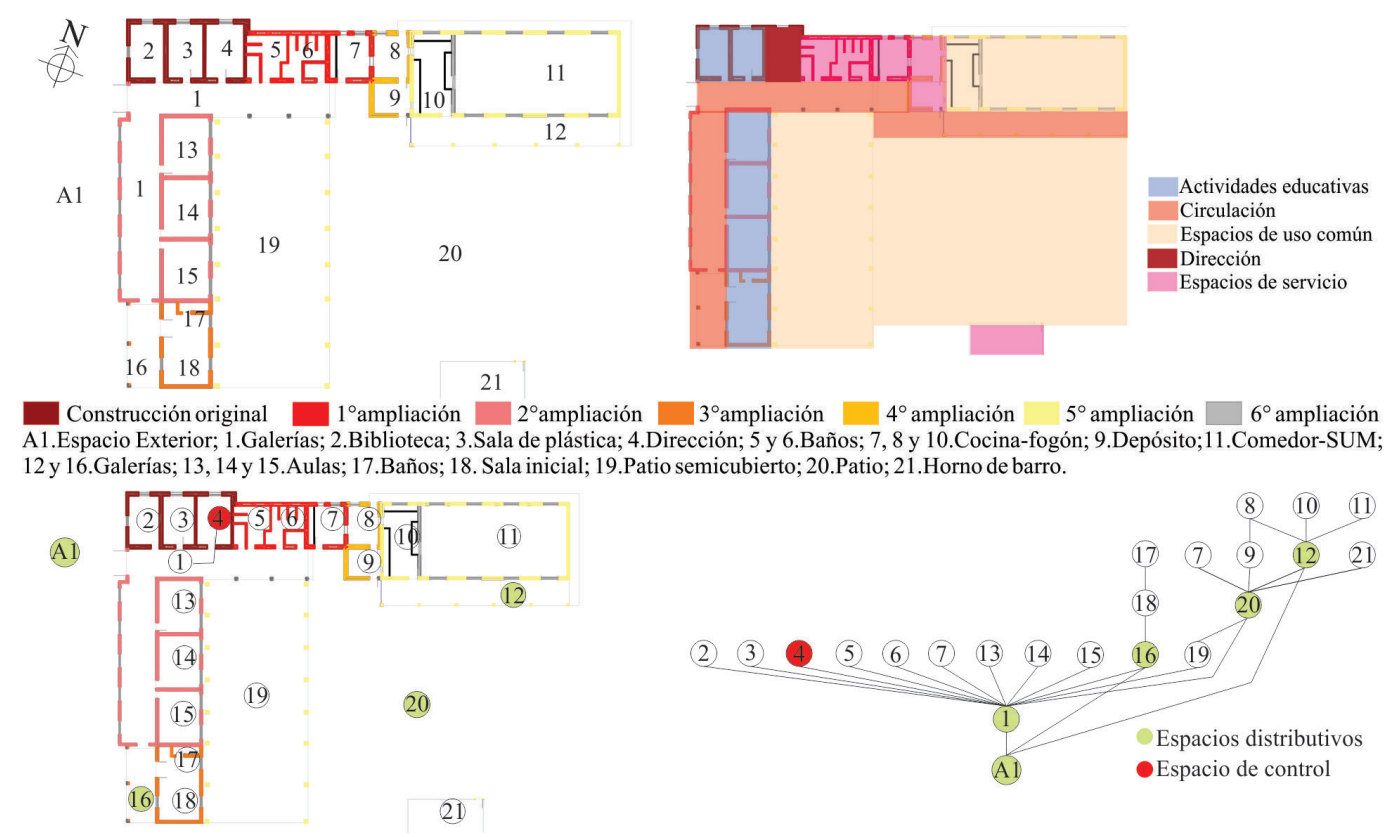

Fuente: Elaboración propia con base en planos facilitados por la Dirección de Materiales y Construcciones Escolares, Ministerio de Educación de Tucumán.

La escuela presenta una planta en "L". Esta diagramación permite que tenga dos patios (uno cubierto y otro abierto) y al mismo tiempo se abra al paisaje exterior. A diferencia de las otras escuelas, las aulas abren a una galería y no a los patios.

El análisis permite diferenciar varias áreas de uso: actividades educativas, áreas de uso común, circulaciones, zonas de servicio y dirección. Los tres niveles comparten las instalaciones, aunque el nivel inicial tiene acceso independiente. En general, presenta una distribución espacial de menor complejidad que los ejemplos anteriores, se puede presumir que esto está en relación directa a la inexistencia del albergue de alumnos y docentes.

$\mathrm{Al}$ analizar el modelo Gamma, se corrobora nuevamente una estructura de tipo panóptico. El espacio exterior, galerías y patio descubierto son los espacios que se jerarquizan. Nuevamente, el espacio de control es la dirección y como en los otros casos está en relación directa al principal espacio distribuidor, las galerías, y está en un sector privilegiado para vigilar de forma integral lo

EntreDiversidades. Revista de Ciencias Sociales y Humanidades, Vol. 9, Núm. 1 (18), enero-junio 2022. Páginas: $46-75$ ISSN-e: 2007-7610. https://doi.org/10.31644/ED.V9.N1.2022.A02 
que sucede en la institución. La menor complejidad de esta escuela también se observa en el no desplazamiento de la función de control en la espacialidad.

Luego de analizar las tres escuelas se observan algunas similitudes entre estas y las viviendas de la zona, principalmente las construcciones originales o las primeras ampliaciones que fueron realizadas por los mismos pobladores con las tecnologías constructivas y patrones de asentamiento locales. Esta similitud se ve debilitada con las ampliaciones llevadas a cabo por los organismos provinciales y el nacional, enmarcadas en Programas gubernamentales. En cuanto al uso de los espacios, se observa que tanto en las escuelas como en las viviendas, el comedor, la cocina y el fogón son de uso común y en ellos se comparte una parte importante de las actividades diarias.

Con respecto a los modelos Gamma se puede decir que las tres poseen una estructura espacial no distributiva, cuentan con dos o tres espacios centrales a los cuales se vinculan los demás espacios, y se las puede caracterizar como estructuras arquitectónicas de tipo panóptico, principalmente la escuela de Lara (actual). En cuanto a las posibilidades de circulación, la escuela de Norco es la que permite una mayor alternativa. En referencia a los espacios de control, aunque las tres escuelas presentan un espacio físico en el que funciona la dirección primaria y secundaria, en lo cotidiano el control y vigilancia se efectiviza desde otros espacios — la cocina, el comedor, la sala de reuniones, los dormitorios de preceptores-.

\section{Festividades en las comunidades y en las escuelas. Costumbres-ritos culturales ancestrales de las comunidades indígenas}

Las comunidades indígenas se caracterizan por tener muy presentes sus costumbres-ritos culturales ancestrales vinculadas a la tradición andina, todas ellas relacionadas a las actividades productivas y al vínculo que establecen con la naturaleza a través de la madre tierra, la Pachamama. Estas ceremonias se realizan en coexistencia a las prácticas religiosas provenientes del credo católico, una herencia de los procesos de sincretismo de la América colonial que sigue vigente. En este trabajo se consideraran aquellas festividades relacionadas con los ritos ancestrales, diferenciando las actividades espirituales de las productivas.

\section{Ceremonias de La Pachamama y el Inti Raymi}

La Pachamama se celebra el 1 de agosto, representa a la naturaleza y a la tierra divinizada, como la madre de todos y la generadora de vida; se lleva a cabo con el propósito de pedir y agradecer por las buenas cosechas y el bienestar del ganado. Se realiza en esta fecha porque corresponde con la época en que termina el invierno y las heladas, y las plantas empiezan a brotar. La celebración se realiza de forma comunitaria en algún espacio sagrado para la comunidad y también en la intimidad de cada familia — casas, puestos, corrales — . Principalmente, consiste en cavar un pozo en la tierra, "la boca de la madre tierra", y depositar en él distintos alimentos y bebidas a modo de ofrendas. Durante la ceremonia también se realiza una "sahumada"12 al espacio físico y a cada uno de los invitados. Ese día llegan personas desde distintos puntos del territorio. La celebración

${ }^{12}$ Se preparan sahumos con hierbas de la zona como ruda, romero, laurel o lavanda y se encienden ese día.

EntreDiversidades. Revista de Ciencias Sociales y Humanidades, Vol. 9, Núm. 1 (18), enero-junio 2022. Páginas: $46-75$ ISSN-e: 2007-7610. https://doi.org/10.31644/ED.V9.N1.2022.A02 
suele durar todo el día, por la mańana se "abre y cierra la boca de la madre tierra", luego se hace un almuerzo con las comidas y bebidas que trajo cada uno de los invitados o que prepararon las mujeres en el sitio y más tarde se realizan los juegos ancestrales. Al margen del momento de la celebración, la referencia a la Pachamama está presente en la vida cotidiana de estas comunidades.

Otro evento que cobra importancia es la Ceremonia de Inti Raymi o La fiesta del sol el 21 de junio. Esta tradición, herencia de los pueblos incas, fue recuperada hace algunos años por la comunidad de Potrero Rodeo Grande. Coincide con el solsticio de invierno y es considerada el año nuevo andino. La celebración consiste en hacer una vigilia durante los primeros rayos del sol en un lugar sagrado de la comunidad alrededor de una fogata grande.

Ambas ceremonias forman parte de los rituales tradicionales andinos, donde convergen aspectos espirituales — sol y madre tierra como deidades_- necesidades de las comunidades campesinas — lluvias, fertilidad y cosechas_, la importancia de la relación armoniosa con la naturaleza y la organización familiar-productiva-comunitaria.

\section{Yerra, Señalada y Corrida}

Otras actividades ancestrales están relacionadas directamente con las actividades productivas como la yerra, seńalada y corrida. Se realizan en las inmediaciones de cada corral familiar cuando necesitan marcar, vacunar y/o castrar el ganado. Aunque la familia dueña de los animales es quien organiza todo el evento, la comunidad participa de forma activa. Se empieza al medio día y suele durar hasta el otro día. Al inicio del evento se eligen los mejores ejemplares de cada especie, se los adorna con flores y se los "casa". A medida que los hombres jóvenes realizan las actividades productivas, las mujeres van preparando el almuerzo. Después, se hacen algunos juegos, con premios y multas - como tomar un vaso de vino ${ }^{13}$ - y también se baila, se canta y se toca algún instrumento.

En todos estos eventos es importante la presencia de la comida y de la bebida —maíz, mazamorra, queso de cabra, locro, carne, yerbeao, vino-, así como del espíritu comunitario, el baile, el canto y la música tradicional como coplas, bagualas, vidalas ${ }^{14}$ y música folclórica en general acompañados por cajas, guitarras y flautas. En algunas ocasiones se invitan a personas externas a la comunidad que trabajan en el territorio como técnicos y profesionales de los CAPS o de las escuelas. Al igual que las prácticas espirituales estos eventos integran funciones sociales, simbólicas, espirituales, económicas y lúdicas, a la vez que fortalecen los vínculos comunitarios.

\section{Celebraciones "oficiales" en las escuelas}

Entre las festividades que se celebran en las escuelas abordadas podemos diferenciar aquellas de fechas patrias y las de acontecimientos sociales-culturales de identidad escolar y comunitaria. Es habitual la participación de toda la comunidad educativa, familias de las localidades, incluso aunque no tengan hijos en la institución, y actores externos a la comunidad —autoridades

\footnotetext{
${ }^{13}$ La mazamorra y el locro son comidas tradicionales de Argentina a base de maiz blanco. El yerbeao es una bebida a base de yerba mate y agua ardiente.

${ }^{14}$ Las bagualas y vidalas son ritmos musicales folcóricos tradiconales del noroeste de Argentina.
}

EntreDiversidades. Revista de Ciencias Sociales y Humanidades, Vol. 9, Núm. 1 (18), enero-junio 2022. Páginas: 46-75 ISSN-e: 2007-7610. https://doi.org/10.31644/ED.V9.N1.2022.A02 
municipales-provinciales, bomberos con la banda de música, cura, turistas, "enduristas", ${ }^{15}$ entre otros_. En las celebraciones más importantes llegan a participar alrededor de 60 personas en Lara, 160 en Norco y 130 en Gonzalo. La mayoría de las festividades demandan una organización general con un mes de antelación que incluye "buscar precios", juntar fondos a través de rifas y comprar mercadería, regalos y la torta — su presencia es fundamental en todos los festejos(tareas de docentes y directores); elegir el menú y la preparación de la comida (tareas de las madres, quienes preparan y cocinan todo en la escuela); organizar los juegos y obtener fondos para el cotillón (tarea de los alumnos, principalmente del nivel secundario); y ocuparse de las actividades de la parrilla y armar los mesones (tarea de los padres). Las familias también suelen colaborar aportando carne, leña o gas envasado.

\section{Fechas Patrias}

Estas festividades corresponden a los días de: La Memoria por la Verdad y la Justicia (24 de marzo), el Veterano y los Caídos en la Guerra de Malvinas (2 de abril), la Revolución de Mayo (25 de mayo), aniversario de la muerte del General Manuel Belgrano y la Bandera (20 de junio), Declaración de la Independencia (9 de julio), aniversario de la muerte del General José de San Martín (17 de agosto), aniversario de la Batalla de Tucumán (24 de septiembre), Diversidad Cultural (12 de octubre), la Tradición (10 de noviembre) y la Soberanía Nacional (20 de noviembre).

En las escuelas de alta montaña, el día de la Revolución de mayo — 25 de mayo - es una de las fechas más importantes. Como se mencionó, todas estas escuelas tenían un ciclo lectivo especial por las condiciones climáticas de montańa, con clases de agosto a mayo; por tal razón la fiesta de fin de año coincidía con esta fecha patria. Y aunque actualmente en Tucumán solo la escuela de Lara mantiene esta particularidad, sigue siendo una fecha importante para todas las escuelas y comunidades de la zona. Ese día inicia en la mañana el acto, con distintas actividades artísticas —obras de teatro, bailes, poesías, etc.—, al medio día se hace un almuerzo y en la tarde se hacen juegos de la silla con caballos y enlazada. ${ }^{16}$

\section{Acontecimientos sociales de la comunidad educativa}

Los acontecimientos sociales relacionados con la identidad de la comunidad educativa corresponden a los actos de inicio y finalización de clases, días del Maestro (11 de septiembre), del Estudiante (21 de septiembre) y las celebraciones de cumpleaños, de la Virgen o Patrono del lugar y de la Familia.

El día del Maestro se festeja desde hace cinco años aproximadamente. Se hace un acto por la mańana, luego un almuerzo y por la tarde se realizan los juegos — con harina, globos y enlazado- - El día del Estudiante se celebra hace seis o siete años. La celebración incluye diversas

\footnotetext{
${ }^{15}$ Personas de la provincia o turistas que suelen subir a estas zonas en motocicletas de enduro. En la zona son nombrados como "enduristas".

${ }^{16}$ Juegos tradicionales del lugar. El juego de la silla con caballos es como el juego de la silla infantil, donde se ponen varias sillas en el medio y se baila alrededor; en este caso, se hace con caballos. Enlazada se refiere a enlazar animales que llevan los miembros de la comunidad.
}

EntreDiversidades. Revista de Ciencias Sociales y Humanidades, Vol. 9, Núm. 1 (18), enero-junio 2022. Páginas: 46-75 ISSN-e: 2007-7610. https://doi.org/10.31644/ED.V9.N1.2022.A02 
actividades que fortalecen los vínculos de la comunidad educativa: fogones, guitarreadas, cantos, cuentos, "aro-aro", ${ }^{17}$ chistes, guerra de canciones, fiesta de disfraces y bailes de cotillón, y se comparten pizzas, hamburguesas, pollos, papas fritas y torta. La celebración de cumpleaños de los alumnos se celebra dos veces al año. Se preparan "bolsitas" con obsequios, piñatas, gorritos, globos, carteles, comida, torta y juegos. Estas festividades se realizan como iniciativa de los docentes y entremezclan prácticas urbanas y locales de la comunidad.

La celebración del día de la Virgen es una de las celebraciones más importantes para las comunidades desde los puntos de vista espiritual, cultural e histórico y cada comunidad tiene su santo o virgen particular. Estas celebraciones y misas se hacen en la escuela porque es el espacio de mayor superficie en la zona y puede albergar a toda la comunidad. En Lara se celebra en el mes de diciembre, en Norco en enero, cerca de la celebración de "Los Reyes Magos", y en Gonzalo en febrero. El cura que oficia la misa es de Trancas y sube una o dos veces al año a cada zona, por lo que se aprovecha su viaje y se hacen bautismos, comuniones, confirmaciones y hasta casamientos, ya sea en la escuela o en la capilla de la zona, generalmente ubicada a pocos metros de la escuela. En el caso particular de Lara, hay tres capillas, por lo que el cura antes de llegar al plantel y a la última capilla - la que se encuentra al frente al edificio escolar - hace un recorrido por las otras capillas y el territorio a modo de procesión acompañado por la virgen y la comunidad. La celebración en la escuela dura todo el día, primero se hace la misa y luego el almuerzo y los juegos.

La celebración del día de la Familia se realiza solo en los planteles escolares de Norco y Gonzalo en el mes de octubre. Es una de las festividades más importantes para la comunidad, nacida de la iniciativa de los docentes. Durante la mañana se hace una misa, luego el almuerzo y torta y después se llevan a cabo juegos — lotería, rifas, etc.—, bailes folclóricos y por último se entregan regalos a las familias. Estos regalos suelen ser objetos para la casa.

\section{Las celebraciones en el calendario}

$\mathrm{Al}$ analizar cómo se suceden en el tiempo las festividades propias de las comunidades y las de las escuelas se observa la importante recurrencia de festejos y encuentros durante todo el ańo. Incluso las superposiciones entre ambas se resuelven para que las familias participen de todos los eventos. Ejemplo de ello ocurre en el mes de mayo, cuando alguna familia organiza una Yerra o Señalada, en las escuelas se festeja el día de la Revolución de Mayo y en la escuela de Lara se realiza el acto de finalización del año lectivo. Esta simultaneidad de actividades demanda que las familias se organicen y se desplacen por distintos sectores del territorio en un tiempo relativamente corto. El hábito de la trashumancia en las comunidades es aprovechado y predispone a los miembros de la comunidad a desplazarse por todo el territorio a lo largo del año para atender estos y otros compromisos.

\footnotetext{
${ }^{17}$ Entre algunas canciones los cantores dicen algunas frases o historias breves con intención de hacer reír.
}

EntreDiversidades. Revista de Ciencias Sociales y Humanidades, Vol. 9, Núm. 1 (18), enero-junio 2022. Páginas: 46-75 ISSN-e: 2007-7610. https://doi.org/10.31644/ED.V9.N1.2022.A02 
Figura 10. Festividades ancestrales, fechas patrias y festividades culturales

\begin{tabular}{|c|c|c|c|c|c|c|c|c|c|c|c|}
\hline ENERO & FEBRERO & MARZO & ABRIL & MAYO & JUNIO & JULIO & AGOSTO & SEPTIEMBRE & OCTUBRE & NOVIEMBRE & DICIEMBRI \\
\hline $\begin{array}{c}\text { YERRA } \\
\text { SEÑ. } \\
\text { CORRIDA }\end{array}$ & \begin{tabular}{|c|} 
YERRA \\
SEÑ. \\
CORRIDA \\
\end{tabular} & $\begin{array}{c}\text { YERRA } \\
\text { SEÑ. } \\
\text { CORRIDA }\end{array}$ & \begin{tabular}{|c|} 
YERRA \\
SEÑ. \\
CORRIDA \\
\end{tabular} & $\begin{array}{c}\text { YERRA } \\
\text { SeÑ. } \\
\text { CORRIDA } \\
\end{array}$ & INTIRAYMI & & $\begin{array}{l}\text { PACHA } \\
\text { MAMA }\end{array}$ & & & & $\begin{array}{c}\text { YERRA } \\
\text { SEÑ. } \\
\text { CORRIDA } \\
\end{array}$ \\
\hline & & $\begin{array}{c}\text { DE LA } \\
\text { MEMORIA }\end{array}$ & $\begin{array}{c}\text { DE LAS } \\
\text { MALVINAS }\end{array}$ & \begin{tabular}{|c|} 
REVOLUCIÓN \\
DE MAYO
\end{tabular} & $\begin{array}{c}\text { DE LA } \\
\text { BANDERA }\end{array}$ & $\begin{array}{c}\text { DE LA } \\
\text { INDEPENDE } \\
\text { NCIA }\end{array}$ & $\begin{array}{l}\text { SAN } \\
\text { MARTIN }\end{array}$ & $\begin{array}{l}\text { SARMIENTO } \\
\text { BATALLA DE } \\
\text { TUCUMÁN }\end{array}$ & $\begin{array}{l}\text { DIVERSIDAD } \\
\text { CULTURAL }\end{array}$ & $\begin{array}{c}\text { TRADICIÓN } \\
\text { Y } \\
\text { SOBERANIA }\end{array}$ & \\
\hline $\begin{array}{l}\text { VIRGEN } \\
\text { ÑORCO }\end{array}$ & $\begin{array}{c}\text { VIRGEN } \\
\text { GONZALO }\end{array}$ & $\begin{array}{c}\text { INICIO DE } \\
\text { CLASES }\end{array}$ & & $\begin{array}{c}\text { FIN DE } \\
\text { CLASES } \\
\text { LARA }\end{array}$ & $\begin{array}{c}\text { CUMPLEAÑO } \\
\mathrm{S}\end{array}$ & & \begin{tabular}{|c|} 
INICIO DE \\
CLASES \\
LARA
\end{tabular} & $\begin{array}{l}\text { MAESTRO Y Y } \\
\text { ESTUDIANTES }\end{array}$ & $\begin{array}{c}\text { DE LA } \\
\text { FAMILIA }\end{array}$ & CUMPLEAÑOS & $\begin{array}{l}\text { VIRGEN } \\
\text { LARA }\end{array}$ \\
\hline
\end{tabular}

Fuente: Elaboración propia.

Como se observa, se presenta un solapamiento de actividades, ritos y celebraciones de diferente origen y marcos culturales que compromete tanto a las comunidades indígenas como a las educativas. Sin embargo, el solapamiento no debería interpretarse de manera directa como integración social en todos los casos (aunque tampoco como un conflicto) debido a que el proceso no es del todo sinérgico. Esta cuestión se observa al abordar los roles que los actores sociales involucrados desempeñan en las distintas festividades.

\section{Actores y roles en las celebraciones sociales}

Al centrar el análisis en los actores sociales que participan en las festividades se pueden diferenciar roles que se asumen y que cambian en función del ámbito de celebración. Las madres y mujeres de la comunidad indígena son participantes comunes en ambos tipos de celebraciones, y al mismo tiempo las que menos flexibilidad tienen en su rol.

Figura 11. Actores, roles y actividades

\begin{tabular}{|c|c|c|c|c|c|c|c|c|}
\hline \begin{tabular}{|l} 
FESTIVIDADES \\
ROLES
\end{tabular} & Anfitrión & $\begin{array}{l}\text { Organización } \\
\text { general }\end{array}$ & $\begin{array}{l}\text { Organización } \\
\text { comida }\end{array}$ & $\begin{array}{c}\text { Provisión de } \\
\text { alimentos }\end{array}$ & \begin{tabular}{|l|}
$\begin{array}{l}\text { Organización } \\
\text { música }\end{array}$ \\
\end{tabular} & \begin{tabular}{|c|} 
Organización \\
ornamentación
\end{tabular} & Participantes & Otros Participantes \\
\hline Pachamama - Inti Raymi & La comunidad & $\begin{array}{c}\text { Cacique y Consejo } \\
\text { de ancianos }\end{array}$ & Madres & $\begin{array}{l}\text { Miembros de la } \\
\text { comunidad }\end{array}$ & $\begin{array}{c}\text { Músicos de la } \\
\text { comunidad }\end{array}$ & Las familias & $\begin{array}{l}\text { Miembros de } \\
\text { la comunidad } \\
\end{array}$ & $\begin{array}{l}\text { Directores, docentes } \\
\text { y otras instituciones }\end{array}$ \\
\hline Yerra, señalada y corridas & La familia & $\begin{array}{c}\text { Los dueños de } \\
\text { casa }\end{array}$ & Madres & $\begin{array}{l}\text { Miembros de la } \\
\text { comunidad }\end{array}$ & $\begin{array}{c}\text { Músicos de la } \\
\text { comunidad }\end{array}$ & Las familias & $\begin{array}{l}\text { Miembros de } \\
\text { la comunidad }\end{array}$ & $\begin{array}{l}\text { Directores, docentes } \\
\text { y otras instituciones }\end{array}$ \\
\hline $\begin{array}{l}\text { Revolución de mayo, cumpleaños, } \\
\text { inicio y fin de clases, día del } \\
\text { maestro, estudiante y familia }\end{array}$ & La escuela & $\begin{array}{l}\text { Directores y } \\
\text { docentes }\end{array}$ & Madres & $\begin{array}{c}\text { Directores, } \\
\text { docentes y familias }\end{array}$ & $\begin{array}{l}\text { Directores y } \\
\text { docentes }\end{array}$ & $\begin{array}{l}\text { Directores y } \\
\text { docentes }\end{array}$ & $\begin{array}{l}\text { Miembros de } \\
\text { la comunidad }\end{array}$ & $\begin{array}{c}\text { Bomberos, enduristas } \\
\text { autorides estatales }\end{array}$ \\
\hline $\begin{array}{l}\text { Día de la Virgen o patrono de la } \\
\text { localidad }\end{array}$ & El cura & $\begin{array}{c}\text { Directores y } \\
\text { docentes }\end{array}$ & Madres & \begin{tabular}{|c|} 
Directores, \\
docentes y familias
\end{tabular} & $\begin{array}{c}\text { Directores y } \\
\text { docentes }\end{array}$ & $\begin{array}{l}\text { Directores y } \\
\text { docentes }\end{array}$ & $\begin{array}{l}\text { Miembros de } \\
\text { la comunidad }\end{array}$ & $\begin{array}{c}\text { Bomberos, enduristas } \\
\text { autorides estatales }\end{array}$ \\
\hline
\end{tabular}

Fuente: Elaboración propia.

También se observa que tanto la figura del cacique como la del consejo de ancianos, referentes políticos de las comunidades indígenas, solo participan con un rol protagónico en las ceremonias espirituales de la comunidad, mientras que en las festividades productivas cumplen el mismo rol que los otros miembros de la comunidad y los que toman un rol protagónico son los dueños del ganado. En las festividades de las escuelas no tienen participación.

EntreDiversidades. Revista de Ciencias Sociales y Humanidades, Vol. 9, Núm. 1 (18), enero-junio 2022. Páginas: $46-75$ ISSN-e: 2007-7610. https://doi.org/10.31644/ED.V9.N1.2022.A02 
Respecto a las festividades que se celebran en la escuela son los directores y docentes quienes toman un rol protagónico. La figura del cura solo está presente en las celebraciones de la religión católica, tomando un rol protagónico de anfitrión. En las otras celebraciones los directores, docentes y miembros de otras instituciones participan de forma pasiva y no necesariamente como representantes de dichas instituciones.

\section{Las celebraciones sociales en el espacio}

$\mathrm{Al}$ analizar los usos de los espacios en las escuelas durante las festividades se puede hacer una distinción entre las acciones previas al festejo y los del día del festejo (Figura 13). Las actividades previas se realizan principalmente en los comedores, ya que son los espacios cubiertos más amplios y cómodos y permiten la participación de todos. Otros de los espacios usados en estas instancias son las cocinas, cocina solar, parrillas, fogones y salas de reuniones.

Figura 12. Espacios usados días previos y durante los festejos

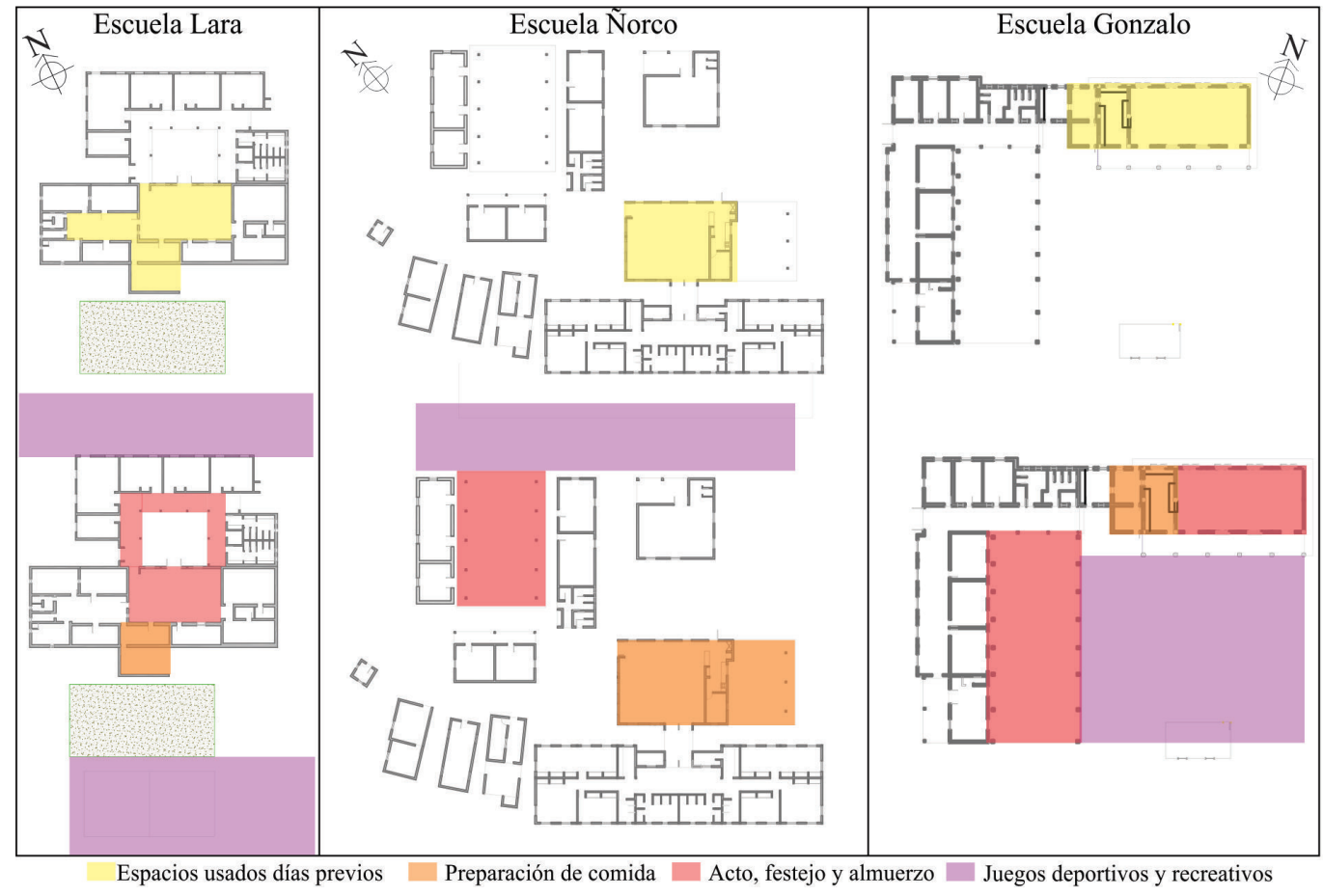

Fuente: Elaboración propia con base en planos facilitados por la Dirección de Materiales y Construcciones Escolares, Ministerio de Educación de Tucumán. 
Durante el día del festejo, el uso de los espacios transcurre en una dinámica casi secuencial entre la cocina, el comedor, las galerías, los patios, las canchas y el espacio exterior.

En la escuela de Lara, las madres usan la cocina y las parrillas de la capilla para terminar de preparar la comida. El comedor se usa como salón para los actos y ceremonias; debido a que el comedor resulta pequeño se arman las mesas para el almuerzo en el comedor (adultos) y en las galerías (alumnos). En el espacio exterior suceden las actividades recreativas. El patio interno prácticamente no se usa para estos eventos puesto que es un espacio pequeńo y cerrado, por lo que funciona como patio de iluminación y ventilación.

En la escuela de Norco los espacios más usados son la cocina, el fogón y el comedor. En el patio se realizan los actos, las ceremonias, los almuerzos, cenas y bailes. La cancha de fútbol y voleibol se la usa para otras actividades recreativas como los juegos ancestrales. Uno de los aspectos que se destacan durante las entrevistas es la fluidez espacial y visual que existe desde el patio con el entorno inmediato y el paisaje natural. A pesar de la rigurosidad del clima durante algunos momentos del año y de la existencia de un espacio cerrado, mantienen el uso de este espacio para los eventos más importantes.

En la escuela de Gonzalo, dos de los espacios más usados también son la cocina y el horno de barro. Otro de los espacios que se usa es el patio semicubierto, en donde se realiza el acto o misa y luego se hace el almuerzo — en los días de lluvia o frío este espacio es reemplazado por el comedor- También destaca el patio descubierto, en donde se hacen los juegos deportivos y recreativos.

El uso de los espacios en las celebraciones de las comunidades indígenas y educativas presenta un gran paralelismo que se puede apreciar al comparar tales dinámicas. Tanto en las viviendas como en las escuelas, la cocina con el fogón y el horno de barro toman un rol protagónico desde antes del festejo y constituyen el espacio del que se apropian las madres. La forma de organización y resolución de las comidas por parte de las mujeres es algo propio de estas comunidades y puede superar las fronteras institucionales — hacen uso de ellas con la misma dinámica con la que se despliegan en las cocinas de sus casas-. Pero son los espacios de uso común los que toman rol protagónico por su carga funcional y simbólica en todas las festividades. Estos espacios, que en lo cotidiano son patios, canchas deportivas o corrales, se transforman para albergar los rituales de las celebraciones. Generalmente son espacios amplios que permiten una fluidez espacial y visual con el paisaje circundante y ese vínculo con la naturaleza tan importante para las comunidades.

\section{Discusión}

A partir del análisis realizado, es posible corroborar que más allá de las diferencias formales, funcionales y espaciales entre las tres escuelas, incluso considerando las modificaciones que tuvieron a lo largo del tiempo, comparten estructuras arquitectónicas de tipo panóptico, como es preponderante en la arquitectura escolar argentina. Ciertamente, como reconocen diversos autores (Pineau, et al., 2007; Vital, 2014; Sasiain, 2015), esto responde a la función principal con la que fueron creadas y diseñadas en general las escuelas estatales en la Argentina. Estas estructuras, entendidas por Zarankin (2001) como no democráticas, están pensadas como dispositivos de

EntreDiversidades. Revista de Ciencias Sociales y Humanidades, Vol. 9, Núm. 1 (18), enero-junio 2022. Páginas: $46-75$ ISSN-e: 2007-7610. https://doi.org/10.31644/ED.V9.N1.2022.A02 
poder que facilitan los procesos de control, normalización y disciplinamiento que el Estado aplica en los procesos de enseñanza formal y formación ciudadana, creando unas verdaderas "máquinas de enseñar" en los términos de Pineau, Dussel y Caruso (2001); son estructuras propias de todas las instituciones en las que se busca disciplinar a los cuerpos mediante un control, estableciendo jerarquías en lugares de encierro como lo que ocurre en cárceles y hospitales (Foucault, 2002). Escolano (1992) y Vital (2014) dicen al respecto que las estructuras arquitectónicas, la distribución de los espacios y las organizaciones de jerarquías en las instituciones educativas no son neutrales, por el contrario, son dispositivos que instituyen un discurso, determinan sistemas de relaciones y sistemas de poder. En las escuelas analizadas los espacios de control se van desplazando en función de quienes ejercen el poder y de las actividades que se desarrollan: cuando están los directores y durante horas de clase el poder se ejerce desde las direcciones, en sus ausencias y durante todo el día lo ejercen los docentes desde cocinas, comedores y sala de reuniones, y a la hora de dormir, los preceptores nocturnos desde los albergues. En el ámbito urbano las escuelas que mejor expresan la estructura panóptica son las que presentan un diseño arquitectónico encerrado hacia el interior del establecimiento, adoptando un férreo control de la comunicación con el exterior y generando un aislamiento de la vida institucional con el contexto. Es la voluntad de diseño formal que se expresa en la actual escuela de Lara, con una estructura arquitectónica compacta que se cierra hacia el interior, conformando espacios comunes en el centro del edificio y negando el entorno. Y es la que lo diferencia sustancialmente con las escuelas de Gonzalo, Norco y la estructura original de esta escuela, donde la fluidez espacial y visual son componentes funcionales y simbólicos propios de la arquitectura doméstica local. Estas estructuras arquitectónicas de alguna manera reproducen la forma en que estas comunidades habitan y se mueven en el territorio.

Las comunidades indígenas históricamente establecieron una relación directa con su entorno natural, poniendo en práctica una serie de conocimientos para transformar la naturaleza con lógicas distintas a la cultura occidental hegemónica. Esta lógica permitió construir su territorio y reconocer sus límites a partir de los hábitos de trashumancia propios de sus actividades productivas agro-ganaderas, donde los animales son el elemento social y simbólico que organiza temporalidades y espacialidades (Benedetti y Tomasi (comps.), 2014; Racedo, et al., 2015). Del mismo modo, esta relación que se establece con el medio inmediato también se observa en la importancia de la "madre tierra" en sus espiritualidades y festividades, principalmente la celebración de la Pachamama; y en sus viviendas a través del uso de materiales naturales-locales, la relación espacial-visual con el exterior, el uso del patio como el organizador de la vida cotidiana y la integración de corrales y huertas al espacio familiar. Y este valor social, cultural, simbólico, histórico y económico de la relación que establecen las comunidades indígenas rurales con su territorio es referido recurrentemente (Haesbaert, 2013; Benedetti y Tomasi (comps.), 2014; Racedo, et al., 2015). Paradójicamente, estos elementos son solo parcialmente tomados en cuenta en las festividades escolares. Esto se observa con mayor claridad al no incorporar la celebración de la Pachamama en el calendario de las festividades escolares y con ello las dinámicas sociales y espaciales que implica. La falta de integración de esta festividad habla de algunas contradicciones de los Estados nacional y provincial respecto a lo que sus Constituciones señalan relativo a la importancia del reconocimiento de sus espiritualidades y la interculturalidad en el marco de

EntreDiversidades. Revista de Ciencias Sociales y Humanidades, Vol. 9, Núm. 1 (18), enero-junio 2022. Páginas: $46-75$ ISSN-e: 2007-7610. https://doi.org/10.31644/ED.V9.N1.2022.A02 
una educación que busca superar las desigualdades y reconocer la existencia de las comunidades indígenas (CNA, 1994; CPT, 2006; LEN, 2006).

Durante las festividades, los espacios de comedor y cocinas, al igual que los de patios y canchas, son los que cobran relevancia y en donde toda la comunidad se reúne. Estos, se encuentran jerarquizados espacial y funcionalmente en las estructuras arquitectónicas de las escuelas y en el transcurso de los eventos este protagonismo se ve potenciado. Y aunque las estructuras arquitectónicas de las tres escuelas permiten que estas actividades festivas se pongan en práctica, algunos elementos arquitectónicos identificados limitan y obstaculizan el desarrollo funcional de estas formas y relaciones sociales. Es lo que ya se señaló en la actual escuela de Lara. Tras la ampliación realizada en el año 2010 el patio propuesto resultó pequeño para reunir a toda la comunidad, se perdió su importancia y funcionalidad como el centro simbólico de las festividades y pasó a ser prácticamente un espacio residual, de servicio o ventilación, resultando obsoleto desde su misma concepción. Esto muestra claramente que al momento de planificar la ampliación de la escuela se reprodujo la esencia espacial propia del rol disciplinador del Estado y la estructura arquitectónica de las escuelas urbanas (Zarankin, 2001) sin tomar en consideración las particularidades de la comunidad local, sus formas de habitar o sus dinámicas culturales. Esta forma de actuar sobre el espacio de la escuela interpela la percepción espacial y funcional de las propias espacialidades construidas por las comunidades indígenas rurales y se reproducen prácticas históricas de estigmatización sobre sus modos de vida y saberes. Estos modos de proceder del Estado sobre la arquitectura escolar analizada también señalan ciertas contradicciones con los Criterios y Normativa Básica de Arquitectura Escolar (CyNBAE, 1998) y con la Ley de Educación Nacional (LEN, 2006), documentos anteriores a la ampliación. En estos documentos se acentúa la importancia de considerar las variables territoriales al momento de diseñar una escuela, para así lograr una estructura arquitectónica que permita fortalecer los valores culturales e identitarios y las actividades productivas locales.

Las festividades en las escuelas, aunque son "oficiales" y las encontramos en la mayoría de las instituciones escolares de la Argentina, adoptan particularidades a partir de las dinámicas sociales de estas comunidades. Están presentes en el uso del espacio, en las actividades que se desarrollan, en la organización y duración de los eventos, en la comida, los juegos, la música, el baile y el canto; pero, en especial, es posible identificar mayores particularidades en los actores, sus roles y la participación comunitaria en general. Si bien los roles principales son asumidos por las autoridades educativas —o religiosas, dependiendo de la festividad a celebrar-, hay una redistribución de otros roles, como el de las madres y su función en la cocina y en la elección del menú —en correspondencia con los hábitos cotidianos y festividades locales_- Estos hechos reproducen ese hábito y el rol de la mujer en las comunidades indígenas, quienes cumplen la función principal dentro del espacio familiar y consagran la importancia de las cocinas y en especial de los fogones en la vivienda. La presencia del fogón en las viviendas es el símbolo de vida en la montaña y es el espacio en el que se comparten historias y se consolidan vínculos (Racedo, et al., 2015; Pazzarelli, 2016). Precisamente, esto es lo que ocurre en las festividades escolares, la presencia de las mujeres y de la comida es uno de los elementos principales que permiten

EntreDiversidades. Revista de Ciencias Sociales y Humanidades, Vol. 9, Núm. 1 (18), enero-junio 2022. Páginas: $46-75$ ISSN-e: 2007-7610. https://doi.org/10.31644/ED.V9.N1.2022.A02 
consolidar los vínculos entre la comunidad escolar y la comunidad indígena; sin su presencia activa, las festividades en las escuelas de montańa perderían su singularidad frente a las escuelas urbanas.

Tanto las festividades ancestrales de la comunidad como las festividades escolares son hechos que interpelan a todo el territorio. Los miembros de la comunidad se desplazan hacia puntos específicos donde se hacen las celebraciones y el espacio exterior y la naturaleza forman parte integrante de estos eventos. En el desarrollo de estas festividades es fundamental la organización de toda la comunidad donde cada miembro cumple un rol y se encarga de una tarea específica. Así, se ponen en práctica pautas culturales y dinámicas que consolidan los vínculos de cooperación y ayuda mutua sobre la que se fundan sus principios sociales (Racedo, et al., 2015). Y aunque en las festividades escolares se rescata la importancia de la distribución de roles y el trabajo comunitario, el modo en que se eligen roles y actores resulta arbitrario y no democrático, en contraste a la organización mediante asambleas que las comunidades adoptan. Los miembros de la comunidad asumen sus tareas desde un lugar subalterno, asumiendo aquellos roles que la dinámica escolar les asigna y con una participación mayormente pasiva en la toma de decisiones sobre la organización. A su vez, llama poderosamente la atención que siendo la comunidad educativa abierta a la participación de otros actores ajenos a la comunidad educativa - como los "enduristas" o curas - dos actores fundamentales de la comunidad indígena como el cacique y el consejo de ancianos — sus representantes políticos- están ausentes en los festejos. En las festividades de carácter religioso que se realizan en las escuelas el cura toma un rol protagónico y es reconocido como tal, como una autoridad de la iglesia católica, mientras que tanto el cacique como el consejo de ancianos, referentes de la comunidad local, no constituyen una entidad activa ni pasiva en el evento, sino la negación lisa y llana. Y aunque desde hace algunas décadas las comunidades indígenas lograron un respaldo legal para defender sus derechos, las desigualdades y la negación de su existencia como otra nación persisten en el tiempo y en el territorio. Esta ausencia de reconocimiento de sus referentes y de sus instituciones políticas por parte del Estado es un claro ejemplo de ello. La organización política de una comunidad indica cómo se estructura, cómo se distribuye el poder en el territorio, quiénes son los que toman las decisiones, cómo fueron elegidos y cuáles son las prioridades de la comunidad para su desarrollo; resulta ser una parte fundamental de la identidad de toda comunidad y, por lo tanto, negarla es rechazar su integridad y la participación activa en la toma de decisiones sobre sus políticas públicas.

En consonancia con lo anterior, las festividades que se celebran en las escuelas hacen alusión principalmente a momentos históricos "oficiales" de la Argentina y a aspectos de la religión católica, pero dejan de lado aquellas festividades que son parte de la identidad e idiosincrasia de estas comunidades indígenas como lo es la celebración de la Pachamama. En la ausencia de incorporar las festividades ancestrales al calendario escolar es posible observar nuevamente una actitud de negación e indiferencia hacia las costumbres culturales de estas comunidades indígenas por parte del Estado que se torna recurrente, actitud que se reitera cuando se decidió — por una simplificación en la administración pública para que la mayoría de las escuelas de la provincia compartan el ciclo lectivo - cambiar el ciclo lectivo de montaña. Entre las consecuencias de esta modificación, se perdió el simbolismo que existía entre la finalización del año lectivo y la fiesta

EntreDiversidades. Revista de Ciencias Sociales y Humanidades, Vol. 9, Núm. 1 (18), enero-junio 2022. Páginas: $46-75$ ISSN-e: 2007-7610. https://doi.org/10.31644/ED.V9.N1.2022.A02 
del 25 de mayo, una práctica que se realizaba hace casi 100 ańos en el territorio. Festividad que a pesar de ser propia de la sociedad occidental se instaló hace muchos ańos en las escuelas y hoy forma parte de la vida social e histórica del territorio.

En definitiva, cada uno de estos hechos dan muestra de que el Estado es quien continúa determinando y delimitando territorialidades, relaciones sociales, prácticas culturales y espacialidades de las comunidades indígenas rurales, mediante mecanismos de imposición, desvalorización y estigmatización (Arenas y Ataliva, 2017; Trinchero, 2010). El Estado, a través de sus instituciones, rutinas y leyes — de manera más o menos coercitiva - regula, moldea, organiza y define la cultura, modos en que la vida social puede ser vivida, identidades, relaciones e interrelaciones entre sujetos construidas a lo largo de la historia. De igual manera, niega o suprime las prácticas culturales, las identidades y las interrelaciones sociales de las comunidades dominadas y subordinas por este (Corrigan y Sayer, 2007). Lo que finalmente buscan las agencias estatales es homogeneizar y estandarizar a las comunidades en una sola sociedad bajo la lógica de una única nación y para ello recurren a la negación de la legitimidad de otras prácticas y modos de vida. Es por esta razón que la instituciones estatales, entre ellas la escuela, fueron convertidas en agencias estatales dentro de un proceso histórico en el que el Estado fue ganando el lugar de ser el único en atribuir autoridad y tener la razón. Esto es lo que ocurre con algunos de los aspectos en la dinámica del espacio social de las escuelas en las comunidades indígenas analizadas, y que se manifiesta principalmente en el no reconocimiento de sus referentes políticos y sociales, sus manifestaciones espirituales y sus espacialidades y modos de habitar en el ámbito de la escuela. En definitiva, como señala Foucault (2002), es en el espacio de la escuela, en las prácticas y en las relaciones que se construyen, en donde se establecen las disputas de poder del Estado soberano y de las resistencias dominadas.

\section{Conclusión}

Se buscó relacionar las estructuras arquitectónicas de las escuelas con las espacialidades y festividades de las comunidades indígenas involucradas y el uso del espacio institucional, los actores y sus roles en las festividades de las escuelas. La originalidad del tema está justamente en esta relación y en el tomar como casos de estudio escuelas que se encuentran aisladas del sistema educativo en contextos de comunidades indígenas.

Luego de haber analizado las estructuras arquitectónicas de las escuelas en las mismas considerando las espacialidades y festividades de las comunidades indígenas y educativas, se observa que el Estado aún adeuda desarrollar en la práctica aquellas intenciones expresadas en sus discursos, de respetar las particularidades culturales de las comunidades y de reconocer sus ritos y territorialidades. Incluso con los avances y más allá de las variantes que se encuentran en los modos de vivir el espacio social durante las festividades y en las estructuras arquitectónicas de estas escuelas, persiste una actitud homogeneizadora, normalizadora y disciplinante del Estado por sobre las comunidades indígenas y el territorio que es preciso seguir identificando y poniendo en discusión.

EntreDiversidades. Revista de Ciencias Sociales y Humanidades, Vol. 9, Núm. 1 (18), enero-junio 2022. Páginas: $46-75$ ISSN-e: 2007-7610. https://doi.org/10.31644/ED.V9.N1.2022.A02 
A partir de este trabajo también se concluye que la participación comunitaria de las comunidades indígenas es una de sus herramientas esenciales y fundamentales para el desarrollo de su vida, defender sus derechos y sobreponerse a los obstáculos de los dispositivos arquitectónicos e institucionales.

La mayoría de estas festividades forman parte del calendario escolar de escuelas urbanas y rurales de toda la Argentina, por lo que los avances de este trabajo y los procesos identificados pueden servir para análisis que se realicen en otras realidades escolares, principalmente en zonas con comunidades indígenas rurales organizadas. Además, para incentivar a continuar reflexionando sobre las características espaciales, materiales y funcionales que debería presentar la arquitectura escolar estatal en estos contextos.

\section{Bibliografía citada}

Alejandre Jiménez, Susel Noemí, Maikel José Ortiz Bosch y Rafael Claudio Izaguirre Remón (2018). "La relación cultura geográfica-espacio geográfico en la formación de la identidad cultural”. Nadir: Revista electrónica de geografía austral [en línea], Año 10, Núm. 1, pp. 1-9. Disponible en: http://revistanadir.yolasite.com/resources/ARTICULO\%20SUSEL\%20 ALEJANDRE\%20NADIR.pdf (Consultado el 9 de octubre de 2020).

Arenas, Patricia (2013). "La participación de Tucumán en el relevamiento territorial de la Ley 26160: una mirada desde las prácticas”. Población y sociedad [en línea], 20 (2), pp. 125136. https://cerac.unlpam.edu.ar/index.php/pys/article/view/2986uj (Consultado el 11 de abril de 2020).

Arenas, Patricia y Ataliva, Victor (2017). Las comunidades indigenas: etnoterritorios, prácticas y saberes ancestrales. Buenos Aires, Argentina: Ediciones Imago Mundi.

Benedetti, Alejandro y Tomasi, Jorge (comps.) (2014). Espacialidades altoandinas. Nuevos aportes desde la Argentina. Miradas hacia lo local, lo comunitario y lo doméstico. Buenos Aires, Argentina: Facultad de Filosofía y Letras Universidad de Buenos Aires.

Capel, Horacio (2016). "Las ciencias sociales y el estudio del territorio". Biblio3W. Revista Bibliográfica de Geografía y Ciencias Sociales [en línea], 21 (1.149). Disponible en: http:// www.ub.edu/geocrit/b3w-1149.pdf (Consultado el 9 de octubre de 2020).

Castellanos, Cecilia, et al. (2018). "Los Valles Calchaquíes y los Diaguitas: Procesos históricos, desigualdades y disputas identitarias”. Revista Voces en el Fénix [en línea], Núm. 72, pp. 22-29. Disponible en: https://vocesenelfenix.economicas.uba.ar/los-valles-calchaquiesy-los-diaguitas-procesos-historicos-desigualdades-y-disputas-identitarias/ (Consultado el 11 de noviembre de 2020).

Constitución de la Nación Argentina (CNA) (1994). Constitución de la Nación Argentina, 22 de agosto de 1994 [en línea]. Disponible en: https://pdba.georgetown.edu/Parties/Argentina/ Leyes/constitucion.pdf (Consultado el 10 de octubre de 2020).

EntreDiversidades. Revista de Ciencias Sociales y Humanidades, Vol. 9, Núm. 1 (18), enero-junio 2022. Páginas: 46-75 ISSN-e: 2007-7610. https://doi.org/10.31644/ED.V9.N1.2022.A02 
Constitución de la Provincia de Tucumán (CPT) (2006). Constitución de la provincia de Tucumán [en línea]. Disponible en: http://rig.tucuman.gov.ar/obras publicas/compras-2017/ normativa archivos/Constitucion\%202006.pdf (Consultado el 20 de octubre de 2020).

Corrigan, Philip y Sayer, Derek (2007). "La formación del Estado inglés como revolución cultural”, en Lagos, M. y Calla, P. (comps.). Antropología del Estado. Dominación y prácticas contestatarias en América Latina. La Paz, Argentina: Cuaderno de Futuro Núm. 23, pp. 39-116.

Criterios y Normativa Básica de Arquitectura Escolar (CyNBAE) (1998). Criterios y normativa básica de arquitectura escolar [en línea]. Disponible en: https://www.educ.ar/ recursos/114117/criterios-y-normativa-basica-de-arquitectura-escolar/download/inline (Consultado el 7 de agosto de 2020).

Di Méo, Guy (1998). Géographie sociale et territoires. Paris, France: Nathan.

Escolano, Agustín (1992). “Tiempo y educación. Notas para una genealogía del almanaque escolar”. Revista de educación [en línea], Núm. 298, pp. 55-79. https://www.educacionyfp. gob.es/dam/jcr:83a05b1f-d85d-48ce-a5ff-5dc544cc4cdb/re2980300486-pdf.pdf (Consultado el 7 de septiembre de 2020).

Foucault, Michel (2002). Vigilar y castigar: Nacimiento de la prisión. Buenos Aires, Argentina: Siglo XXI editores Argentina.

Garay, Ana (2018). Hábitat rural y condiciones de vida en Tucumán. Tesis para obtener el grado de Doctorado en Ciencias Sociales, Facultad de Filosofía y Letras, Universidad Nacional de Tucumán. Disponible en: https://ri.conicet.gov.ar/handle/11336/78933 (Consultado el 8 de agosto de 2020).

Guibert, Marta A. de (1988). Historia de la educación Argentina. Desde la época colonial hasta la iniciación del primer periodo de la Organización Nacional. Buenos Aires, Argentina: Ministerio de Educación y Justicia.

Haesbaert, Rogério (2013). "Del mito de la desterritorialización a la multiterritorialidad". Cultura y representaciones sociales [en línea], 8 (15). Disponible en: http://www.culturayrs.unam. mx/index.php/CRS/issue/view/39 (Consultado el 10 de octubre de 2020).

Instituto Nacional de Estadística y Censos (INDEC) (2021). Población, Estructura de la población [en línea]. Disponible en: https://www.indec.gob.ar/indec/web/Nivel3-Tema-2-18 (Consultado el 10 de octubre de 2020).

Isla, Alejandro (2002). Los usos politicos de la identidad. Indigenismo y Estado. Buenos Aires, Argentina: Editorial de las Ciencias.

Ley de Educación Común (LEC) (1884). Ley reglamentando la Educación Común $N^{\circ} 1420$ [en línea]. Disponible en: http://www.bnm.me.gov.ar/giga1/normas/5421.pdf (Consultado el 5 de diciembre de 2021).

Ley de Educación Nacional (LEN) (2006). Ley de Educación Nacional N²6.206 [en línea]. Disponible en: https:/www.argentina.gob.ar/sites/default/files/ley-de-educ-nac58ac89392ea4c.pdf (Consultado el 6 de julio de 2020).

Lobato, Mirta Zaida y Suriano, Juan (2000). Nueva historia Argentina. Atlas histórico. Buenos Aires, Argentina: Editorial Sudamericana. 
Ministerio de Culturay Educación (McyE) (1996). Accionespara la Transformación Educativa 19941996 [en línea]. Buenos Aires, Argentina: Ministerio de Cultura y Educación. Disponible en: http://www.bnm.me.gov.ar/giga1/documentos/EL002612.pdf (Consultado el 8 de noviembre de 2020).

Ministerio de Desarrollo Productivo de Tucumán (MDPT) (2020). Comunidades indigenas con territorios reconocidos. Provincia de Tucumán [en línea]. Disponible en: http://rides. producciontucuman.gov.ar/comunidades-indigenas-con-territorios-reconocidos-provde-tucuman/ (Consultado el 10 de octubre 2020).

Ministerio de Planificación Federal, Inversión Pública y Servicios (MPFIPyS) (2016). Disponible en: https://www.argentina.gob.ar/normativa/nacional/ resoluci\%C3\%B3n-363-2004-96828/texto (Consultado el 10 de octubre de 2019).

Organización Internacional del Trabajo (OIT) (2014). Convenio $N^{\circ} 169$ sobre pueblos indígenas y tribales en paises independientes en 1989 [en línea]. Lima, Perú: Organización Internacional del Trabajo América Latina y el Caribe. https:/www.ilo.org/wcmsp5/groups/public/--americas/---ro-lima/documents/publication/wcms 345065.pdf (Consultado el 9 de octubre de 2020).

Pazzarelli, Francisco Gustavo (2016). "La equivocación de las cocinas: humos, humores y otros excesos en los Andes meridionales". Revista de Antropología [en línea], 59 (3), pp. 49-72. doi: https://doi.org/10.11606/2179-0892.ra.2016.124805 (Consultado el 10 de noviembre de 2020).

Pineau, Pablo, Inés Dussel y Marcelo Caruso (2001). La escuela como máquina de educar. Tres escritos sobre un proyecto de la modernidad. Buenos Aires, Argentina: Paidós.

Pineau, Pablo, et al. (2007). A cien años de la Ley Láinez. Buenos Aires, Argentina: Ministerio de Educación, Ciencia y Tecnología.

Plencovich, María Cristina y Costantini, Alejandro (coords.) (2011). Educación, ruralidad y territorio. Buenos Aires, Argentina: Ciccus.

Racedo, Josefina, et al. (2015). Conociendo la comunidad indigena Los Chuschagastas. Tierra, organización comunitaria e identidad. San Miguel de Tucumán, Argentina: Facultad de Filosofía y Letras Universidad Nacional de Tucumán.

Santos, Milton (1996). Metamorfosis del espacio habitado. Barcelona, España: Oikos-Tau.

Santos, Milton (2000). La naturaleza del espacio: Técnica y tiempo. Razón y emoción. Barcelona, España: Ariel.

Sasiain, Sonia (2015). "Espacios que educan: tres momentos en la historia de la educación en Argentina”. Cuadernos del Centro de Estudios en Diseño y Comunicación [en línea], Núm. 52, pp. 287-300. doi: https://doi.org/10.18682/cdc.vi52.1352 (Consultado el 10 de octubre de 2020).

Tedesco, Juan Carlos (2003). Educación y sociedad en la Argentina (1880-1945). Buenos Aires, Argentina: Siglo XXI.

EntreDiversidades. Revista de Ciencias Sociales y Humanidades, Vol. 9, Núm. 1 (18), enero-junio 2022. Páginas: 46-75 ISSN-e: 2007-7610. https://doi.org/10.31644/ED.V9.N1.2022.A02 
Trinchero, Héctor Hugo (2010). "Los pueblos originarios en Argentina. Representaciones para una caracterización problemática". Cultura y representaciones sociales [en línea], Año 4, Núm. 8, pp. 111-139. Disponible en: http:/www.scielo.org.mx/pdf/crs/v4n8/20078110-crs-4-08-00111.pdf. (Consultado el 7 de julio de 2020).

Varela Freire, Gabriela S. (2019). "Incidencia de las variables territoriales en el funcionamiento de las escuelas rurales de muy difícil acceso". En: XIII Jornadas de Sociología. Buenos Aires, Argentina: Universidad de Buenos Aires. También disponible en: https://cdsa. aacademica.org/000-023/536.pdf

Vińao Frago, Antonio (1993). "Del espacio escolar y la escuela como lugar: propuestas y cuestiones". Historia de la educación [en línea], Vol. 12-13, pp. 17-74. Disponible en: https://revistas.usal.es/index.php/0212-0267/article/view/11367/11786 (Consultado el 6 de julio de 2020).

Vital, Susana Noemí (2014). "La organización del tiempo y el espacio en el aula escolar. La propuesta de enseñanza de la lectura de Luis Iglesias”. En: $1^{\circ}$ Encuentro Internacional de Educación. Tandil, Argentina: Facultad de Ciencias Humanas, Universidad Nacional del Centro de la Provincia de Buenos Aires. Disponible en: https://1library.co/document/ zp07040q-ensenanza-lectura-escritura-experiencia-pedagogica-fortunato-iglesiasorganizacion.html (Consultado el 8 de septiembre de 2020).

Zarankin, Andrés (2001). Paredes que domesticam: Arqueologia da arquitectura escolar capitalista: o caso de Buenos Aires. Tesis para obtener el grado de Doctorado en Historia, Instituto de Filosofía y Ciencias Humanas, Universidad Estatal de Campinas. 